(C) The Author(s), 2021. Published by Cambridge University Press on behalf of The Nutrition Society. This is an Open Access article, distributed under the terms of the Creative Commons Attribution licence (http://creativecommons.org/licenses/by/4.0/), which permits unrestricted re-use, distribution, and reproduction in any medium, provided the original work is properly cited.

\title{
Epigenetic linkage of systemic lupus erythematosus and nutrition
}

\author{
Tatiana Montoya, María Luisa Castejón, Rocío Muñoz-García and Catalina Alarcón-de-la-Lastra* \\ Department of Pharmacology, Faculty of Pharmacy, Universidad de Sevilla, 41012 Sevilla, Spain
}

\section{Abstract}

The term 'epigenetics' refers to a series of meiotically/mitotically inheritable alterations in gene expression, related to environmental factors, without disruption on DNA sequences of bases. Recently, the pathophysiology of autoimmune diseases (ADs) has been closely linked to epigenetic modifications. In fact, epigenetic mechanisms can modulate gene expression or repression of targeted cells and tissues involved in autoimmune/inflammatory conditions acting as keys effectors in regulation of adaptive and innate responses. ADs, as systemic lupus erythematosus (SLE), a rare disease that still lacks effective treatment, is characterised by epigenetic marks in affected cells. Taking into account that epigenetic mechanisms have been proposed as a winning strategy in the search of new, more specific and personalised therapeutics agents, pharmacology and pharmaco-epigenetic studies about epigenetic regulations of ADs may provide novel individualised therapies. Focusing on possible implicated factors on development and predisposition of SLE, diet is feasibly one of the most important factors since it is linked directly to epigenetic alterations and these epigenetic changes may augment or diminish the risk of SLE. Nevertheless, several studies have suggested that dietary therapy could be promising to SLE patients via prophylactic actions deprived of side effects of pharmacology, decreasing co-morbidities and improving lifestyle of SLE sufferers. Herein, we review and discuss the cross-link between epigenetic mechanisms on SLE predisposition and development, as well as the influence of dietary factors on regulation of epigenetic modifications that may eventually make a positive impact on SLE patients.

\section{Keywords: Autoimmune disease: Epigenetic: Nutritional therapy: Systemic lupus erythematosus}

(Received 12 January 2021; revised 28 July 2021; accepted 10 August 2021)

\section{Introduction}

Epigenetics has been defined as a series of reversible and inheritable alterations capable of regulating genetic expression and stability. These mechanisms support cellular growth, development and differentiation, but they do not disrupt DNA sequences of bases ${ }^{(1)}$. The epigenetic settings may be orchestrated by several factors such as the aging process or environmental influences such as smoke, climate, nutrition, viral infections, chemical exposures, etc. ${ }^{(2)}$. Three main epigenetic mechanisms involved are DNA methylation, histone modifications and noncoding RNA profiling (Fig. 1).

1. DNA methylation. DNA methylation is the most traditional and well-known epigenetic event. It is involved in several pathologies, considered as a basic process of cellular development and growth. This procedure involves the transference of a methyl group from $S$-adenosylmethionine (SAM) to $5^{\prime}$-carbon position of cytosine residues in cytosine-phosphate-guanosine $(\mathrm{CpG})$ dinucleotides on DNA strand. The CpG islands are located near promoter regions and transcription start sites. For that reason, the methylated CpGs sites result in inaccessible heterochromatin for transcription effectors, inducing genic silencing. Contrarily, the non-methylated sequences remain accessible, and transcription goes on ${ }^{(3,4)}$. DNA methylation is executed by DNA methyltransferase
(DNMT) enzymes. According to de novo or maintenance states of methylation, it may be conducted by DNMT3 or DNMT1, respectively.

2. Histone modifications. Histones are proteins that wrap DNA to form nucleosome structures. The main post-translational alterations of histones are acetylation/deacetylation, methylation/demethylation, phosphorylation and ubiquitination. These modifications at terminal amino acid modulate the accessibility to transcriptional factors and gene expression ${ }^{(5)}$. Some studies have postulated a relation between DNA methylation and histone modifications that reorganises chromatin and blocks gene expression ${ }^{(6)}$.

3. Noncoding RNAs (ncRNAs). Long noncoding (lnc) ( $>200$ nucleotides) and short ncRNAs (miRNA) ( $<200$ nucleotides) modulate expression or repression at the transcriptional and post-transcriptional level, regulating chromatin formation, histone modifications and DNA methylation. miRNAs have been extensively studied in autoimmune and chronic inflammation, being postulated as biomarkers and therapeutic targets. In addition, miRNAs bind to complementary target mRNAs and suppress translation by degradation of this target ${ }^{(7)}$.

The maintenance of proper function and balance between epigenetic processes is essential to normal development and action of immune system. However, increasing evidence has shown that epigenetic deregulated modifications, including DNA

* Corresponding authors: calarcon@us.es 


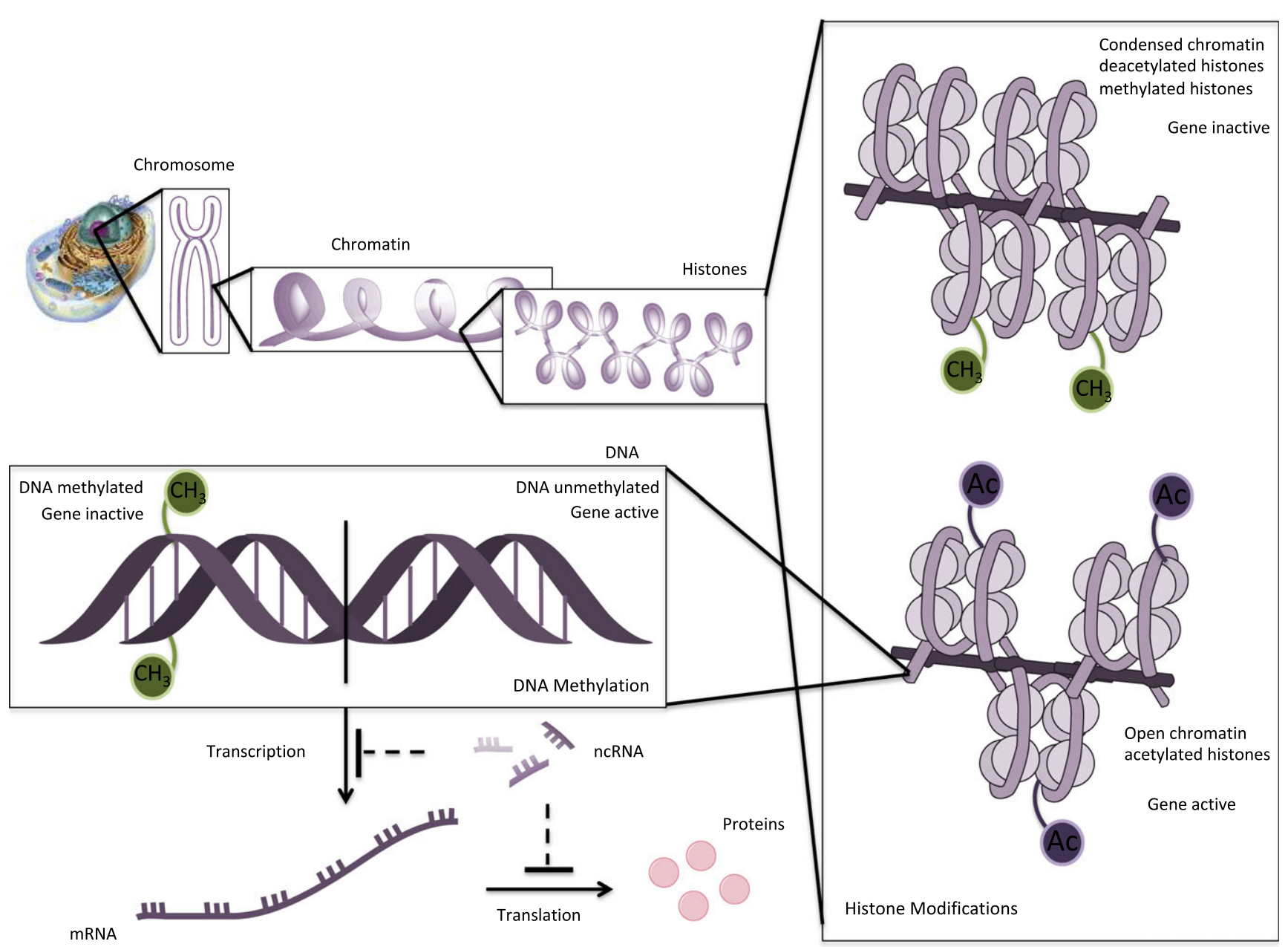

Fig. 1. Schematic epigenetic modifications: histone modifications, DNA methylation and ncRNAs. DNA is wrapped around histones to form nucleosomes. Histone acetylation opens the chromatin, enabling transcription with activation of genes. Contrarily, deacetylation or methylation of histones condenses the chromatin, making it inaccessible for transcription components. DNA methylation is operated by DNMTs that add methyl groups on CpG island in the promoter region of a gene. DNA methylation blocks the binding of transcription factors and results in suppression of gene expression. In unmethylated DNA sequences, the transcription machinery is capable to transcribe and gene is active. ncRNAs regulate gene expression or silencing at the transcriptional or post-transcriptional level.

methylation, histone modification and ncRNAs, are involved in the pathogenesis of several autoimmune diseases (AD). Besides, the alterations of epigenome are implicated in the dysregulation of signalling molecules and receptors of various autoimmune/ inflammatory conditions ${ }^{(6,8)}$. Also, it has been reported that ADs are related to genetic predisposition and environmental factors, whose effects induce epigenetic modifications ${ }^{(9)}$.

Consequently, epigenetic events could play a relevant role in the aetiology and pathogenesis of ADs, even promising a potential future therapeutic intervention. In fact, it has been proposed as a plausible strategy in the research of new therapeutic agents that are more specific and personalised. Thus, pharmacologic and pharmaco-epigenetic studies on reversible epigenetic regulations of autoimmune pathologies to drug responses may provide novel individualised therapies ${ }^{(3,8,9)}$.

ADs like systemic lupus erythematosus (SLE), rheumatoid arthritis (RA), psoriasis or multiple sclerosis, among others, are characterised by epigenetic marks in affected cells ${ }^{(3)}$. Despite the fact that total extension of epigenetic modifications in these pathologies remains unclear, this characteristic could indicate a definitive approach to patients who are exposed to chronic therapy whose side effects can make day-to-day life difficult for patients ${ }^{(7)}$.

Overall, nutrition is one of the most accessible external factors implicated in ADs, so its influence on the epigenetics profile of ADs should be considered. Additionally, the knowledge of micronutrient action in epigenetic patterns of ADs could indicate a promising strategy to prevent them. Nevertheless, the studies that investigate the effects of bioactive compounds in the context of epigenetic alterations have been focused mainly on cancer. Consequently, in the present review, we intend to summarise up-to-date preclinical and clinical studies on epigenome alterations of SLE and discuss the potential roles of epigenetic regulation by dietary bioactive compounds.

\section{Systemic lupus erythematosus (SLE)}

SLE is an autoimmune multiorgan disease characterised by its clinical and pathogenic complexity that can damage different 
organs such as skin, kidneys, joints, lungs, coronary system and liver, among others ${ }^{(10,11)}$. Difficult diagnosis, alternated and unpredictable exacerbation and remission periods during the course of disease, in addition to the high number of complications, affect the patient's quality of life.

This $\mathrm{AD}$ is characterised by loss of tolerance to self-antigens and, thus, overactivation of $\mathrm{B}$ and $\mathrm{T}$ cells, increasing the production of anti-nuclear autoantibodies, immune complex deposition, lymphoproliferation and expression of inflammatory cytokines that may initiate and amplify inflammation, contributing to the clinical manifestations of $\operatorname{SLE}^{(12)}$.

SLE is considered a rare disease, according to EC Regulation on Orphan Medicinal Products. Demographically, the prevalence of the disease is approximately 20-150 cases per 100 000 individuals worldwide. Besides, approximately $90 \%$ of the patients are fertile women between 20 and 30 years old, although it can appear at any age ${ }^{(13,14)}$.

Even though aetiopathogenesis of SLE is not totally defined, genome-wide association studies have revealed several roles to genetic predisposition in lupus patients. However, the discordance for SLE between monozygotic twins described by Deapen et al., in 1992, suggested that other non-genetic factors possibly regulate disease onset ${ }^{(15)}$. Exposure to UV light, smoking, consumption of some drugs or inadequate dietary habits could negatively condition the epidemiology of SLE ${ }^{(10)}$.

Recently, epigenetics has been postulated as an environmental driver that contributes to the aetiology of SLE. In 2010, Javierre and colleagues revealed for the first time that monozygotic discordance on SLE features widespread alterations in DNA methylation status of several genes. Individual analysis confirmed different profiles of methylation and expression in genes related to SLE pathology ${ }^{(16)}$. As a result, discordance between twins allowed the identification of epigenetic targets and highlights their potential contribution to SLE.

The presence of $\mathrm{X}$ chromosomes is positively related to high risk for SLE. Nevertheless, the implicated epigenetic features remain unclear. Recently, Syrett and colleagues have established that the sticking female predilection of this disease is caused by the defective inactivation of $\mathrm{X}$ chromosome. Females normally inactivate one $\mathrm{X}$ chromosome to balance $\mathrm{X}$-linked genes with the male sex ${ }^{(17)}$. The inactivation process is started in early development, where each female cell randomly determines to silence the paternal or maternal X chromosome, by allele-specific up-regulation of the long noncoding RNA (lncRNA) Xist from the future inactive $\mathrm{X}$. Xist RNA recruits heterochromatin modifications (H3K27me3 and H2-ubiquitin) across the $\mathrm{X}$ chromosome, inducing a transcriptional silencing. They observed that Xist RNA disappeared from the X inactive chromosome, and X chromosome inactivation maintenance was altered in the maturation of thymocytes and T-cell subsets from SLE patients and mice. Consequently, SLE patients' T cells exhibited up-regulated X-linked genes ${ }^{(17)}$. Accordingly, the hypomethylation of several genes encoded to X chromosome, such as TRL 7 or CD4OL, which are implicated in the development of immune response, have been described in lupus disease and pathophysiology. In fact, CD40LG, a B-cell co-stimulatory molecule, is overexpressed in lupus lymphocytes and contributes to an exacerbated production of autoantibodies ${ }^{(3,4,6,18)}$.

\section{Variations of epigenome on SLE}

DNA methylation, histone modifications and miRNA expression have been thoroughly defined in in vitro and in vivo experimental studies, using peripheral blood mononuclear cells (PBMCs) of SLE patients or animal models, that have shown that variation of the epigenome may lead to the onset of SLE.

\section{DNA methylation in SLE}

Recent studies have confirmed that DNA hypomethylation is a dominant factor in SLE (Table 1). In consequence, some demethylating agents are known to promote drug-induced experimental lupus ${ }^{(19)}$.

Lupus-like autoimmunity and severity is associated with CD70 (so TNFSF7 encoded) and C11a (so TNFSF5 encoded) overexpression in $\mathrm{CD}_{4}^{+} \mathrm{T}$ cells. This fact has been related to DNA hypomethylation on their respective promoters. CD70 is expressed in activated $\mathrm{T}$ cells and increases IgG synthesis, collaborating in B-cell co-stimulatory functions ${ }^{(20)}$. On the other hand, CD11a (ITGAL encoded) is an integrin implicated in COstimulation and cellular adhesion and also related to leucocyte function-associated antigen (LFA) 1 . Increased LFA1 in T cells from lupus patients involves an autoreactive phenotype of lupus (43). Zhao et al. (2010a) established that the overexpression of CD70 and CD11a in SLE CD4 ${ }^{+}$T cells was the result of the DNMT1 recruitment at the $C D 70$ and $C D 11 a$ promoter region, orchestrated by regulatory factor X (RFX) 1. RFX1 works like an immune-suppressor and is usually decreased in SLE patients' cells, so it seems to be involved in lupus pathogenesis (20). Conclusively, regulation of RFX1 in lupus patients provides a valuable insight into methylation-dependent gene expression on CD70/CD11a axis, which promotes autoimmune response. Furthermore, Luo et al. (2010) compared CD70 expression levels and methylation status of $C D 70$ promoter region in $\mathrm{CD} 4^{+} \mathrm{T}$ cells from patients with subacute cutaneous lupus erythematosus (SCLE) and healthy controls. The results showed a CD70 surface-overexpressed and $C D 70$-demethylated promoter region in $\mathrm{CD}^{+} \mathrm{T}$ cells from SCLE patients compared with cells from healthy subjects, concluding that demethylation of regulatory elements could contribute to the increase of CD70 expression in patients with SCLE ${ }^{(21)}$.

Surprisingly, an interesting in vitro study showed reduced expression of RFX1 in CD4 $4^{+}$T cells from patients with SLE, leading to interleukin (IL) 17A overexpression through decreased DNA methylation. The results revealed that RFX1 deficiency increased the differentiation of naïve $\mathrm{CD} 4^{+} \mathrm{T}$ cells into Th17 cells. Furthermore, the same researchers demonstrated that conditional deletion of $R F X 1$ in mice exacerbated experimental pristane-induced lupus-like syndrome and increased Th17 cell induction. These data revealed that RFX1 functions downstream of the signal transducer and activator of transcription (STAT) 3 and phosphorylated-STAT3, inhibiting their expression, highlighting a non-canonical pathway that regulated differentiation of Th17 cells ${ }^{(25)}$.

Additionally, previous studies have investigated inhibition of DNMT1 activity, confirming the DNA hypomethylation profile is characteristic in lupus cells. Deng and co-workers have shown that $\mathrm{T}$ cells from patients with active lupus had diminished 
Table 1. DNA methylation altered patterns in SLE

\begin{tabular}{|c|c|c|c|}
\hline Experimental system & Target & Action & Reference \\
\hline SLE CD4 ${ }^{+} \mathrm{T}$ cells & $\begin{array}{l}\text { Recruitment of DNMT1 } \\
\text { Hypomethylation of CD70 and CD11a promoter }\end{array}$ & CD70 and CD11a overexpression & (20) \\
\hline CD4 ${ }^{+} T$ cells from SCLE patients & Hypomethylation of $C D 70$ promoter & CD70 overexpression & (21) \\
\hline T cells from SLE patients & DNA hypomethylated at IL 4 and IL 6 promoter regions & $\begin{array}{l}\text { Elevated IL4 and IL } 6 \text { mRNA levels } \\
\text { Association with severity of SLE }\end{array}$ & (22) \\
\hline $\begin{array}{l}\text { CD4 } 4^{+} \mathrm{T} \text { lymphocytes from SLE patients and } \\
\text { human Jurkan T cells }\end{array}$ & Hypomethylated IL $17 F$ promoter region & Regulation of IL17F production & (23) \\
\hline $\begin{array}{l}\text { T cells from SLE and RA patients and healthy } \\
\text { controls }\end{array}$ & $\begin{array}{l}\text { DNMT3 recruitment } \\
\text { Hypomethylation at IL17A promoter }\end{array}$ & IL2/IL17A imbalanced expression levels & (24) \\
\hline $\mathrm{CD}^{+} \mathrm{T}$ cells from SLE patients & DNA hypomethylation & $\begin{array}{l}\text { Reduction of RFX1 expression } \\
\text { IL17A overexpression }\end{array}$ & (25) \\
\hline PBMC from SLE & Low DNA methylation level of $I F I 44 L$ promoter & $\begin{array}{l}\text { Increased IFI44L expression } \\
\text { Different IFI44L levels between SLE patients with or without renal abnormalities }\end{array}$ & (26) \\
\hline SLE CD4 ${ }^{+} \mathrm{T}$ cells & $\begin{array}{l}\text { Increased hydroxymethylation in promoter regions of } \\
\text { SOCS1, NRF2F6, IL15RA }\end{array}$ & $\begin{array}{l}\text { Up-regulation of immune-related genes (SOCS1, NRF2F6, IL15RA) and signal- } \\
\text { ling pathways (Wnt, MAPKs, mTOR) }\end{array}$ & (27) \\
\hline $\begin{array}{l}\mathrm{CD}^{+} \mathrm{CD}^{+} 8^{+} \mathrm{KIR}^{+} \mathrm{CD} 11 \mathrm{a}^{\text {hi }} \mathrm{T} \text { cells from female } \\
\text { SLE patients }\end{array}$ & DNA hypomethylation & Induction of pro-inflammatory and transcriptional profiles in SLE & (28) \\
\hline $\mathrm{CD}^{-} 8^{+}$and $\mathrm{CD}^{-} 8^{-} \mathrm{T}$ cells from SLE patients & DNA hypomethylation & $\begin{array}{l}\text { Aberrant KIR overexpression } \\
\text { IFN overproduction } \\
\text { Induction of macrophage activation }\end{array}$ & (29) \\
\hline SLE T cells & $\begin{array}{l}\text { DNA hypomethylation in } P P 2 A c \text { promoter region } \\
\text { Decreased DNMT1 levels }\end{array}$ & Increment of PP2AC expression and SLE disease activity & (30) \\
\hline T cells from active SLE and inactive SLE patients & Down-regulation of DNMT and DNA hypomethylation & Decrease of signalling Ras-MAPK pathway & (31) \\
\hline $\mathrm{CD} 4^{+} \mathrm{T}$ cells from SLE patients & Global DNA hypomethylation & Low levels of gadd $45 \mathrm{~A}$ and CD11a/CD70 mRNA & (32) \\
\hline SLE CD4 ${ }^{+} \mathrm{T}$ cells & $\begin{array}{l}\text { DNA hypomethylation of regulatory regions of } C D 11 a \\
\text { and } C D 70 \text { genes }\end{array}$ & $\begin{array}{l}\text { Increased high-mobility group box protein } 1 \text { (HMGB1) and CD11a and CD70 } \\
\text { mRNA }\end{array}$ & (33) \\
\hline $\mathrm{CD}^{+}{ }^{+}$and $\mathrm{CD} 8^{+} \mathrm{T}$ cells from active SLE patients & Hypomethylation of $P R F 1$ promoter & Perforin overexpression & (34) \\
\hline SLE women $\mathrm{CD}^{+}{ }^{+} \mathrm{T}$ cells & DNA demethylation of $C D 4 O L G$ and $C D 70$ & $\begin{array}{l}\text { Overexpression of CD40LG mRNA and CD70 } \\
\text { B-cell stimulation and IgG production }\end{array}$ & $(18,35)$ \\
\hline $\mathrm{CD}^{+} \mathrm{T}$ cells from SLE patients & $\begin{array}{l}\text { DNA hypomethylation at } I L-10 \text { and } I L-13 \text { enhancer and } \\
\text { promoter regions }\end{array}$ & $\begin{array}{l}\text { Increased IL } 10 \text { and IL } 13 \text { mRNA and protein expression } \\
\text { Induction of autoantibody production and tissue damage }\end{array}$ & (36) \\
\hline SLE B cells & $\begin{array}{l}\text { Demethylation of } \mathrm{CpG} \text { islands in the } C D 5-E 1 B \text { pro- } \\
\text { moter }\end{array}$ & $\begin{array}{l}\text { Down-regulation of membrane CD5 level } \\
\text { Activation and expansion of autoreactive B cells }\end{array}$ & (37) \\
\hline Blood from SLE women & Hypomethylation of $16 \mathrm{CpG}$ sites in 11 genes & Association with antibody production in SLE & (38) \\
\hline PBMC from SLE with or no LN & $\begin{array}{l}\text { Aberrant DNA methylation in } M X 1, \text { GPR84, E2F2 rel- } \\
\text { evant genes }\end{array}$ & $\begin{array}{l}\text { Increased gene expression (MX1, GPR84, E2F2) } \\
\text { Elevated levels of inflammatory cytokines }\end{array}$ & (39) \\
\hline $\begin{array}{l}\mathrm{CD} 4^{+} \mathrm{T} \text { cells, CD19+ } \mathrm{B} \text { cells and } \mathrm{CD} 14^{+} \text {mono- } \\
\text { cytes from SLE patients }\end{array}$ & Severe hypomethylation in related-IFN genes & IFN-mediated hypersensitivity & (40) \\
\hline SLE CD4 ${ }^{+} \mathrm{T}$ cells & $\begin{array}{l}\text { Global DNA hypomethylation } \\
\text { Low levels of DNMT1 }\end{array}$ & $\begin{array}{l}\text { Modulation of autoimmune response } \\
\text { Aberrant IgG level }\end{array}$ & (41) \\
\hline Whole blood from SLE patients & $C D 3 z$ gene hypermethylation & Correlated with SLE disease activity and clinical manifestations & (42) \\
\hline
\end{tabular}


DNMT mRNA levels decreasing the Ras-mitogen-activated protein kinase (Ras-MAPK) signalling. The inhibition of signalling through the Ras-MAPK pathway with a soluble inhibitor of MAPK ERK I (MEK1) decreased DNMT MRNA and their enzyme activity, similarly to DNA hypomethylation in SLE T cells. These results suggested that a decrease in Ras-MAPK pathway signalling could be involved in down-regulation of DNMT activity in association with DNA hypomethylation in patients with lupus (31). In addition, transgenic mouse with impaired ERK pathway signalling in T cells exhibited low expression of DNMT1 and up-regulation of autoreactivity-related methylation-sensitive genes (CD70, CD11a), increased anti-dsDNA antibodies levels and glomerulonephritis ${ }^{(44-46)}$.

Furthermore, recent studies have confirmed that a catalytic subunit of protein phosphatase 2A (PP2Ac), overexpressed in SLE T cells, is involved in the alteration of DNMT1 activity by the impairment of T-cell phosphorylation of MEK/ERK signalling pathways. Sunahori et al. investigated DNA methylation patterns in the PP $2 A c$ promoter region in SLE T cells, compared with normal T cells. Specifically, in T cells from patients with active SLE, the suppression of PP2Ac increased phosphorylation of signalling pathway upstream of DNMT1 expression and activity and, thus, suppressed CD70 and CD11a expression. They concluded that PP2Ac may be a key target to control the methylation of sensitive genes in SLE T through dephosphorylation of MEK/ERK signalling pathway and activation of DNMT1 ${ }^{(30,47)}$.

However, although there are many clinical studies that support the role of DNA methylation in the pathogenesis of lupus, there are only a few in vivo studies of DNA methylation implication in the development of this autoimmune disorder. In 2007, Sawalha et al. studied the existence of correlation between age-dependent autoimmunity in MRL-lpr mice and the decreased expression of DNMT1 and, consequently, T-cell DNA hypomethylation. They found lower levels of DNMT1 steady state in 16-week-old MRL-lpr mice compared with 5week-old mice. Also, they described that 16-week-old mice presented hypomethylated CpG pairs compared with 5-week-old MRL-lpr mice (48). As a consequence, they concluded that reduced expression of DNMT1 and the corresponding T-cell DNA hypomethylation were correlated directly with the development of age-dependent autoimmunity in MRL/lpr mice.

Additionally, Hedrich et al. investigated CpG-DNA methylation patterns in conserved noncoding sequence regions and proximal promoter region of human IL17F gene in resting and activated naïve $\mathrm{CD}^{+}{ }^{+} \mathrm{T}$ lymphocytes from healthy controls or total T lymphocytes from SLE patients. They observed that SLE $\mathrm{T}$ cells displayed lower degrees of CpG-DNA methylation as compared with control $\mathrm{T}$ lymphocytes in response to $\mathrm{T}$ cells. This fact suggested that IL17F production in human T lymphocytes could be regulated by CpG-DNA methylation ${ }^{(23)}$. In this sense, these researchers also studied epigenetic regulators to diametric expression of IL2 and IL17A, whose tight balance is essential for immune homeostasis. They demonstrated that cAMP response element modulator (CREM) $\alpha$ contributed to epigenetic remodelling of the IL2 and IL17A genes during T-cell differentiation. Furthermore, the epigenetic modulation of IL2 through DNMT3a recruitment resulted in trans-activation and demethylation of $I L 17 A$ promoter. This imbalance between
IL2 and IL17A expression levels is a hallmark characteristic of autoimmune disorders, such as SLE ${ }^{(24)}$.

Other targets analysed to show the potential role of DNA methylation in the regulation of gene expression in SLE were IL4 and ILG transcripts. Mi et al. (2008) studied in T cells isolated from SLE patients and healthy controls changes of DNA methylation in IL4 and ILG promoters. They demonstrated that levels of IL4 and IL6 mRNA transcripts were significantly higher in SLE T cells, as compared with controls. Therefore, hypomethylation of both promoters occurred in T cells from SLE patients and was associated with the severity of SLE ${ }^{(22)}$.

IFI44L is considered a highly sensitive and specific diagnostic marker for SLE. Zhao et al. (2016a) found that methylation level of IFI $44 \mathrm{~L}$ promoter could distinguish patients with SLE from healthy people and other ADs; thus, it could be considered a sensitive and specific diagnostic marker for this pathology. Furthermore, the DNA methylation level within the IFI $44 \mathrm{~L}$ promoter was significantly lower in patients with SLE with renal involvement than in SLE patients without renal abnormalities (26). In this line, stimulatory and killer cell inhibitory immunoglobulin-like receptor (KIR3) was overexpressed in $\mathrm{T}$ cells unmethylated from SLE patients $\left(\mathrm{CD} 28^{+}\right.$and $\left.\mathrm{CD} 28^{-}\right)$, proportionally to degree of disease, through promotion of killing of macrophages and increase in interferon (IFN) $\gamma$ level, suggesting that antibodies to inhibitory KIR may be a treatment for this disease ${ }^{(49)}$.

Overall, the wide study of overexpression of different genes such as CD11a and KIR from CD4 ${ }^{+}$and CD28 ${ }^{+} \mathrm{T}$ cells might explain genetic risk and disease activity in lupus. In fact, $\mathrm{CD}^{+}{ }^{+} \mathrm{CD} 28^{+} \mathrm{KIR}^{+} \mathrm{CD} 11 \mathrm{a}^{\text {hi }} \mathrm{T}$ cells are demethylated and characterised by pro-inflammatory epigenetic and transcriptional profiles in SLE. Thus, it was suggested that removing these cells or blocking their pro-inflammatory outlines could be considered a novel approach to treatment of lupus (28)

On the other hand, Zhao and colleagues (2016) detected increased 5-hydroxymethylxytosine (5-hmC) levels, a novel discovered modified form of cytosine, in genomic DNA in $\mathrm{CD}^{+}{ }^{+} \mathrm{T}$ cells from SLE patients, compared with healthy controls. This result was accompanied by up-regulated expression of teneleven translocation (TET)-2 and TET-3, which can enzymatically convert 5-methylcytosine (5-mc) into 5-hmC. Also, these researchers found differences between DNA hydroxymethylation patterns from SLE patients and healthy controls, such as Wnt, MAPKs or mTOR signalling pathways and selected immune-related genes (SOCS1, NRF2F6 and IL15RA). Finally, they concluded that hydroxymethylation is implicated in aberrant regulation of genes in pathogenesis of SLE; thus, 5-hmC could provide a new tool for treating this disorder ${ }^{(27)}$.

Conclusively, these recent advances have shown that altered DNA methylation patterns have a plausible potential as biomarkers for diagnosis and outcome assessment, as well as objects for target and individualised interventions in SLE ${ }^{(50)}$.

\section{Histone modifications in SLE}

Histones have octamer forms with two of each histone core ( $\mathrm{H} 2 \mathrm{~A}, \mathrm{H} 2 \mathrm{~B}, \mathrm{H} 3$ and $\mathrm{H} 4)$, which wrap DNA around them. This conformation enables the accessibility to transcriptional factors 
and gene expression to be controlled ${ }^{(6,51,52)}$. Until now, the main histone modifications studied in SLE are acetylation and methylation. Both processes are mediated by different enzymes with opposite and reversible functions ${ }^{(53)}$. In the acetylation process, an acetyl group is transferred to lysine residue on N-terminal tail by histone acetyltransferase (HAT) enzymes ${ }^{(6)}$. This modification promotes an accessible chromatin structure, increasing the accessibility of DNA to transcription factors. For this reason, $\mathrm{H} 3$ and $\mathrm{H} 4$ hyperacetylation is commonly associated with gene activation. Contrarily, histone deacetylases (HDACs) catalyse the reverse process, removing acetyl groups and contributing to gene silencing through the condensation of nucleosomes and compaction of chromatin structure ${ }^{(4,54,55)}$. Related to histone methylation, this can affect lysine and arginine residues (56). Histone methyltransferases can add up to three methyl groups. However, depending on methylation degree and residues involved, gene regulation could be up-regulated or repressed $(4,11,53)$. For example, it has been described that hypermethylation of histone 4 lysine 4 trimethylation (H4K4me3) is associated with gene transcription, while $\mathrm{H} 3 \mathrm{~K} 4 \mathrm{me} 3$ presents a repressive effect ${ }^{(43)}$

Interesting studies have established that histone modifications contribute to SLE pathogenesis (Table 2). In fact, some of them have identified aberrant global methylation or acetylation of $\mathrm{H} 3$ and $\mathrm{H} 4$ in SLE patients compared with healthy controls. Nevertheless, the involvement of this epigenetic process in SLE remains unclear.

Monocytes are implicated in atherosclerosis and renal disease, contributing to mortality in SLE patients. Moreover, monocyte dysfunction induces production and response to IFN. In monocytes from lupus patients, global $\mathrm{H} 4$ acetylation of several genes has been reported to be significantly altered $(59,62,63)$. However, more than $50 \%$ of H4-hyperacetylated genes are related to interferon regulatory factor (IRF) 1 . IRF1 is a transcription factor in antiviral and immune response with anti-tumour effects. IRF1 can be induced by IFNs and tumour necrosis factor (TNF)- $\alpha$, suggesting that IFN contributes to SLE pathogenesis (5,85). Sullivan et al. (2007) revealed up-regulated ratios of $\mathrm{H} 4 \mathrm{ac}$ in SLE monocytes at the TNF- $\alpha$ locus compared with healthy controls. They concluded an increased transcription of TNF- $\alpha$, playing a key role in the inflammatory response that is seen in lupus patients ${ }^{(57)}$.

The raised possibility that decreased histone acetylation might contribute to lupus pathogenesis by promoting silencing of some genes has been amply studied. García et al. (2005) described for the first time a global site-specific hypermethylation (except H3K4 methylation) and hypoacetylation in histone $\mathrm{H} 3$ and H4 MRL-lpr/lpr mice in comparison with control MRL/ MPJ mice ${ }^{(83)}$. In agreement, Hu et al. showed that SLE CD $4^{+}$ $\mathrm{T}$ cells had decreased overall acetylation of both $\mathrm{H} 3$ and $\mathrm{H} 4$, and they correlated the negative relation between the degree of $\mathrm{H} 3$ hypoacetylation with SLE disease activity ${ }^{(75)}$.

In early stages of lupus nephritis (LN), Wardowska and colleagues observed a significant decrease in $\mathrm{H} 3 \mathrm{~K} 4 \mathrm{me} 3$ and H3K29me3 marks in dendritic cells that could reveal renal involvement in SLE, serving as distinctive biomarkers in the diagnosis of lupus nephritis and monitoring of renal outcome in SLE patients ${ }^{(53)}$. In this line, $\mathrm{H} 3 \mathrm{~K} 4 \mathrm{me} 3$ has been recognised as a potential biomarker associated to SLE pathogenesis, and it could be a promising target for epigenetic-based lupus therapies.

CREM $\alpha$ alters epigenetic conformation of cytokine gene by way of histone acetylation in active SLE T cells. HDAC is recruited to CRE sites in the IL2 promoter, and IL-2 expression is repressed ${ }^{(86-88)}$. Moreover, hyperacetylation of histone 3 lysine 18 (H3K18) and hypomethylated histone 3 lysine 27 (H3K27) at IL17A-IL17F promoters induce low levels of IL2 and IL17F, while IL17A is overexpressed (23,70,89). Hedrich et al. (2017) agreed with these data and reported an increase in $\mathrm{H} 3 \mathrm{~K} 27 \mathrm{me} 3$ and poor H3K18ac levels at IL2 promoter that silenced IL2 secretion ${ }^{(50)}$.

Liu and colleagues studied in vitro TLR-2-stimulated $\mathrm{CD}^{+}{ }^{+} \mathrm{T}$ cells from SLE patients, and they observed an increment of trimethylation into histone 3 lysine 4 (H3K4me3), and $\mathrm{H} 4$ acetylation together with trimethylated histone 3 lysine 9 (H3K9me3) decreased in the $I L 17 A-I L 17 F$ promoter region ${ }^{(73)}$. These data could confirm that histone modifications in SLE through TLR-2 stimulation promoted IL17A and IL17F expression, developing immune reactivity. Likewise, Apostolidis et al. (2013) reported that PP2Ac, a serine/threonine phosphatase highly expressed in SLE cells, enhanced IL17 gene expression thought H3ac in murine T cells, predisposing glomerulonephritis affection ${ }^{(84)}$.

IL10 is the second cytokine with enhanced expression correlated with disease activity and antibody production in lupus patient's serum and tissues. Hedrich and colleagues investigated STAT3- and STAT5-mediated trans-activation and epigenetics remodelling of $I L 10$ gene related to HAT p300. They concluded that the enhanced activation of STAT3 through transcriptional cofactor p300 produces a competitive replacement of STAT5 in regulatory regions and, consequently, the promotion of IL10 expression ${ }^{(74)}$.

TNF- $\alpha$-induced protein 3 (TNFAIP3) is a key SLE susceptibility gene implicated in the modulation of inflammatory responses through nuclear factor- $\mathrm{B}(\mathrm{NF}-\kappa \mathrm{B})$ pathway. Zhao et al. studied TNFAIP3 expression in $\mathrm{CD}^{+}{ }^{+} \mathrm{T}$ cells and the molecular mechanism underlying TNFAIP3 regulation in the pathogenesis of SLE, suggesting that the down-regulation of TNFAIP 3 in $\mathrm{CD}^{+}{ }^{+} \mathrm{T}$ cells of SLE was probably regulated by demethylation of $\mathrm{H} 3 \mathrm{~K} 4$, which led to a reduced quantity of $\mathrm{H} 3 \mathrm{~K} 4 \mathrm{me} 3$ in the promoter of the TNFAIP3 gene. The dysregulation of TNFAIP3 in $\mathrm{CD}^{+} \mathrm{T}$ cells could play a role in the pathogenesis of SLE by over-production of inflammatory cytokines IFN- $\gamma$ and IL17. Thus, they conclude that TNFAIP3 may provide a promising target for the treatment of SLE in clinical practice ${ }^{(77)}$.

As aforementioned, the expression and activity of the transcription factor RFX1 were decreased in SLE CD4 $4^{+} \mathrm{T}$ cells. Zhao and colleagues demonstrated that RFX1 affected DNA methylation and histone acetylation in $\mathrm{CD} 4^{+} \mathrm{T}$ cells by recruiting the co-repressors DNMT1 and HDAC1 to the CD11a and $C D 70$ promoters, and thereby suppressed their expression. Reducing RFX1 in $\mathrm{CD}^{+}{ }^{+} \mathrm{T}$ cells was enough to induce lupus-like T- and B-cell hyperactivity, whereas overexpressing RFX1 blocked Tcell reactivity. These findings confirm a crucial role for RFX1 in regulating the epigenetic status of T cells, and reveal that autoimmune responses in SLE are responsible in part to RFX1 downregulation. Moreover, these authors showed that reduced expression of the transcription factor RFX1 in $\mathrm{CD}^{+}{ }^{+} \mathrm{T}$ cells from 
Table 2. Histone alterations in SLE

\begin{tabular}{|c|c|c|c|}
\hline Cell source & Histone alterations & Effect & References \\
\hline \multirow[t]{3}{*}{ Human SLE Monocytes } & $\begin{array}{l}\uparrow \mathrm{H} 3 \text { and } \mathrm{H} 4 \text { acetylation at TNF- } \alpha \\
\text { locus } \\
\mathrm{H} 4 \text { Hyperacetylation }\end{array}$ & Incremented maturated monocytes and pro-inflammatory cytokines expression & $(57-59)$ \\
\hline & $\uparrow \mathrm{H} 3 \mathrm{~K} 4 \mathrm{me} 3$ & Alteration of gene expression and IRF1 overexpression & $(60,61)$ \\
\hline & $\begin{array}{l}\uparrow \mathrm{H} 4 \text { acetylation } \\
\text { HAT/HDAC imbalance }\end{array}$ & Altered gene expression; increased IRF1, RFX1, BLIMP1, IL4, INF- $\gamma$ and INF- $\alpha$ levels & $(59,62,63)$ \\
\hline \multirow[t]{16}{*}{ Human SLE T cells } & $\uparrow$ H3K27me3 & Decreased HPK1, INF- $\gamma$ and IgG expression; T-cell overactivation and B-cell overstimulation & (64) \\
\hline & $\begin{array}{l}\uparrow \mathrm{H} 3 \text { acetylation } \\
\uparrow \mathrm{H} 3 \mathrm{~K} 4 \mathrm{me} 2\end{array}$ & $\begin{array}{l}\text { Overexpression of CD70 and CD11; reduction of RFX1 expression; increased autoreactivity and } \\
\text { autoimmmunity }\end{array}$ & $(65,66)$ \\
\hline & $\begin{array}{l}\uparrow \mathrm{H} 3 \text { acetylation } \\
\downarrow \mathrm{H} 3 \mathrm{~K} 9 \mathrm{me} 3\end{array}$ & Overexpression of CD11a, CD70 and RFX1 autoantibody and autoreactivity overstimulation & $(20,25,67)$ \\
\hline & $\downarrow$ H3K27me3 & CD11a overexpression induction of inflammation & $(68,69)$ \\
\hline & $\begin{array}{l}\uparrow \mathrm{H} 3 \mathrm{~K} 18 \mathrm{ac} \\
\downarrow \mathrm{H} 3 \mathrm{~K} 27 \mathrm{me} 3\end{array}$ & $\begin{array}{l}\text { Increased IL17A expression and tissular damage; down-regulated IL17F and IL2 expression and DNA } \\
\text { methylation and DNMT3 activity }\end{array}$ & (70) \\
\hline & $\begin{array}{l}\uparrow \mathrm{H} 3 \mathrm{~K} 18 \mathrm{ac} \\
\downarrow \mathrm{H} 3 \mathrm{~K} 27 \mathrm{me} 3\end{array}$ & Decreased IL-17F expression; induction of tissue damage & (23) \\
\hline & $\begin{array}{l}\uparrow \mathrm{H} 3 \mathrm{~K} 27 \mathrm{me} 3 \\
\downarrow \text { H3K18ac } \\
\downarrow \text { Recruitment of HDAC1 }\end{array}$ & Down-regulation of IL-2 and DNMT3A expression; altered regulatory T lymphocytes; B-cell overactivation & $(6,51,71,72)$ \\
\hline & $\begin{array}{l}\uparrow \mathrm{H} 3 \mathrm{~K} 4 \mathrm{me} 3 \text { and } \mathrm{H} 4 \mathrm{ac} \\
\downarrow \mathrm{H} 3 \mathrm{~K} 9 \mathrm{me} 3\end{array}$ & Up-regulation of IL17A and IL17F levels, CD70, CD40L and TLR2 expression; high immunological reactivity & (73) \\
\hline & $\uparrow$ HAT p300 & Deregulated IL10 and auto-antibodies production; increased tissue damage & (74) \\
\hline & $\uparrow \mathrm{H} 3 \mathrm{~K} 18 \mathrm{ac}$ & & \\
\hline & $\begin{array}{l}\uparrow \mathrm{H} 3 \mathrm{aC} \\
\downarrow \mathrm{H} 3 \mathrm{~K} 9 \mathrm{me} 3\end{array}$ & Low RFX1 expression; augmented IL17, IL6 and pSTAT3 levels & (25) \\
\hline & $\begin{array}{l}\downarrow \text { Global acetylation }(\mathrm{H} 3, \mathrm{H} 4) \\
\downarrow \mathrm{H} 3 \mathrm{~K} 9 \mathrm{me}\end{array}$ & $\begin{array}{l}\text { Decreased CREBBP, CBP, P300, HDAC2, HDAC7, SUV39H2 and EZH2 mRNA levels; increased SIRT1 } \\
\text { mRNA levels }\end{array}$ & (75) \\
\hline & $\downarrow$ H3K9ac, H3K14ac & Down-regulation of CD40L and IgG expression; implemented self-reactivity of CD4 ${ }^{+} \mathrm{T}$ cells and E4BP4 & (76) \\
\hline & $\downarrow \mathrm{H} 3 \mathrm{~K} 4 \mathrm{me}$ & expression & \\
\hline & $\uparrow \mathrm{H} 3 \mathrm{~K} 9 \mathrm{me}$ & & \\
\hline & $\downarrow$ H3K4me3 & Decreased TNFAIP3 mRNA levels; up-regulation of INF- $\gamma$ and IL17 expression & (77) \\
\hline Human SLE TH17 cells & $\begin{array}{l}\uparrow \mathrm{H} 3 \mathrm{~K} 4 \mathrm{me} 3 \\
\downarrow \mathrm{H} 3 \mathrm{~K} 27 \mathrm{me} 3\end{array}$ & Increased IL23 production and PSTAT3 expression & (78) \\
\hline Human SLE Treg cells & $\downarrow \mathrm{H} 3 \mathrm{~K} 27 \mathrm{me} 2$ and $\mathrm{H} 3 \mathrm{~K} 4 \mathrm{me} 3$ & Increased Treg cell differentiation and Foxp3 expression & (79) \\
\hline Human PBMC & Hypermethylation & Down-regulation of HDAC6 levels; disrupted gene expression & (80) \\
\hline Human SLE Dendritic cells & $\downarrow \mathrm{H} 3 \mathrm{~K} 4 \mathrm{me} 3$ and $\mathrm{H} 3 \mathrm{~K} 27 \mathrm{me} 3$ & Increased renal damage and IRF1 production & (53) \\
\hline Human $B$ cells & $\begin{array}{l}\uparrow \mathrm{H} 3 \mathrm{k} 4 \mathrm{me} 3, \mathrm{H} 3 \mathrm{~K} 9 \mathrm{ac} \text { and } \mathrm{H} 3 \mathrm{~K} 14 \mathrm{ac} \\
\downarrow \mathrm{H} 3 \mathrm{~K} 27 \mathrm{me} 3 \text { and } \mathrm{H} 3 \mathrm{~K} 9 \mathrm{me} 3\end{array}$ & Alteration of chromatin decondensation and gene expression & (81) \\
\hline $\begin{array}{l}\text { Human neutrophil extracellular } \\
\text { traps (NET) }\end{array}$ & $\begin{array}{l}\uparrow \text { H4K8ac, H4K12ac, H4K16ac and } \\
\text { H2BK12ac } \\
\uparrow \text { H3K27me3 }\end{array}$ & High apoptosis activity & (82) \\
\hline MRL-Ipr/lpr splenocytes & $\begin{array}{l}\downarrow \mathrm{H} 3 \text { and } \mathrm{H} 4 \text { global acetylation } \\
\uparrow \mathrm{H} 3 \text { and } \mathrm{H} 4 \text { global methylation } \\
\downarrow \mathrm{H} 3 \mathrm{~K} 4 \mathrm{me}\end{array}$ & Aberrant histone codes and pathogenesis & (83) \\
\hline Mouse $\mathrm{CD}^{+}{ }^{+} \mathrm{T}$ cells & $\uparrow \mathrm{H} 3$ acetylation & Increased PP2Ac and IL17 levels; predisposing glomerulonephritis & (84) \\
\hline MRL-Ipr/lp Splenic T CD4 ${ }^{+}$cells & $\begin{array}{l}\downarrow \text { Global H3K9 hypomethylation } \\
\text { Global histone } \mathrm{H} 3 / \mathrm{H} 4 \text { hypoacetylation }\end{array}$ & $\begin{array}{l}\text { Decreased E2H2, p300, CREBP, HDAC7 mRNA levels } \\
\text { Cell apoptosis }\end{array}$ & (75) \\
\hline
\end{tabular}


patients with SLE led to IL17A overexpression through increased histone $\mathrm{H} 3$ acetylation and decreased DNA methylation and trimethylated H3 lysine 9 (H3K9me3) ${ }^{(20,25)}$.

Similarly, H3 acetylation and di-methylated H3 lysine 4 (H3K4me2) levels were significantly augmented in patients with lupus, and both factors were associated with the severity of the disease. Thus, these results showed that aberrant histone modifications within the $C D 70$ promoter could participate in the development of lupus by increasing CD70 expression in $\mathrm{CD}^{+}$ T cells ${ }^{(65,66)}$.

Hematopoietic progenitor kinase 1 (HPK1) is a negative regulator of T-cell-mediated immune responses that could play a role in lupus pathogenesis. Using chromatin immune-precipitation (ChIP) microarray data, Zhang and colleagues (2011) found significantly increased $\mathrm{H} 3 \mathrm{~K} 27 \mathrm{me} 3$ enrichment at the HPK1 promoter of SLE $\mathrm{CD}^{+} \mathrm{T}$ cells in comparison with controls. Consistent with these findings, overexpressing HPK1 in SLE $\mathrm{CD} 4^{+} \mathrm{T}$ cells induced an important reduction in T-cell reactivity. These data could demonstrate that HPK1 may serve as a novel target for effective SLE therapy ${ }^{(64)}$.

\section{nCRNAs in SLE}

ncRNAs regulate gene expression or silence at the transcriptional and post-transcriptional level. miRNAs regulate about $60 \%$ of mRNA, and they are implicated in several ADs such as SLE or $\mathrm{AR}$, among others, whereas IncRNAs act on regulated complex of development and differentiation from different immune cells through expression of active protein ${ }^{(1)}$. Currently, they are considered excellent biomarkers and therapeutic targets in ADs ${ }^{(90,91)}$.

Several preclinical and clinical studies have investigated the role of miRNAs in lupus pathogenesis; however, thus far there has not been much study of lncRNAs. Thus, we have revised the main ncRNA epigenetic modifications described in SLE (Table 3).

Among the main miRNAs postulated as biotargets and related with SLE pathogenesis were miR125a, miR142-3p/5p, miR155, miR21 and miR148, among others. Epigenetic evidence suggests that miR125a expression is decreased in monocytes and PBMCs of SLE patients. In activated T cells, miR125a targets Kruppel-like factor (KLF) 13 and then contributes to regulating the expression of 'regulated upon activation, normal $\mathrm{T}$ cell expressed and secreted' (RANTES), also known as CCL5, a known chemokine associated to inflammatory response ${ }^{(67)}$. Pan et al. (2015) demonstrated that miR-125a was down-regulated in peripheral $\mathrm{CD}^{+}$ T cells of SLE patients, acting as a key regulator that controls Tcell differentiation suppressing STAT3, IL13 and IFN- $\gamma$, several gene factors in $\mathrm{CD}^{+} \mathrm{T}$ cells from miR125a-deficient mice ${ }^{(92)}$. In addition, Smith and colleagues described that IL16 was a direct target for miR125a and observed reduced pulmonary miR125a and enhanced IL16 expression, suggesting the IL16/ miR125a axis as a novel therapeutic target for management of acute lung injury in SLE ${ }^{\text {(93). }}$.

miR146a and miR155 are two of the ncRNAs most involved in ADs through NF- $\mathrm{BB}$ and IFN-dependent conditions. miR146a is a negative regulator of innate immunity that targets interferon regulatory factor (IRF) 5, STAT1, tumour necrosis factor receptor associated factor (TRAF) 6 and IL1 receptor associated kinase (IRAK) 1, which are crucial elements of type I IFN signalling cascade and signal transducers in NF-kB, respectively. In PBMC of SLE patients, miR146a directly repressed the transactivation downstream of type I IFN. Also, inclusion of miR146a into the patient's PBMCs reduced the synchronised activation of the type I IFN pathway ${ }^{(93)}$. In this context, Dai et al. (2008) observed a clear connection between miR146a expression and oestrogen production, related to the higher female prevalence of SLE ${ }^{(90,98)}$.

On the other hand, miR155 regulates B-cell activation and survival, essential parameters for SLE pathogenesis. Aboelenein et al. (2017) defined PU.1, a regulator of B cells that enhances TNF- $\alpha$ production, as a target for miR155 in PBMC and B cells from paediatric SLE patients ${ }^{(95)}$. Furthermore, in vitro and in vivo studies carried out by Xin and colleagues revealed another depleted target gene of miR155, the sphingosine-1phosphate receptor (S1PR) 1. They observed that miR155 deficiency diminished SLE autoimmune inflammation by targeting S1PR1 gene in Faslpr/lpr mice.

Complementarily, the serum levels of IL 4 and IL17A, released by Th2 and Th17 cells, were lower in miR155 (-/-) Fas (lpr/lpr) than in Fas (lpr/lpr) mice. They concluded that miR155 might be a new target for therapeutic management in SLE ${ }^{(96)}$. However, an increment of miR155 expression was confirmed in PBMCs and $\mathrm{CD} 19^{+} \mathrm{B}$ cells, suggesting their use as diagnostic biomarkers for SLE patients ${ }^{(97,114)}$; conversely, Lashine et al. detected lower levels in younger SLE patients. These contradictions could be explained by the heterogeneity of the disease and the differences observed in the pathological stages of this disorder (115). These authors correlated decreased expression of miR155 with IL2 deficiency associated with PP2Ac overexpression. Another miRNA implicated in the pathogenesis of SLE relating to IL2 impaired production is miR31. In fact, miR31 miRNA has been found to be markedly under-expressed in patients with SLE. It targets Ras homologue gene family member A (RhoA), a negative regulator of nuclear factor of activated T cells (NFAT) and cell apoptosis that increases the activity of $I L 2^{(102)}$. Therefore, under-expression of miR31 modulates a low production of IL2 through targeting RhoA in SLE T cells. Thus, deregulation of the miR31/RhoA axis represents a novel molecular mechanism that could counteract the IL2 deficiency in patients with SLE.

Emerging evidence has revealed an association between miRNA and DNA methylation. Some miRNAs such as miR21, miR148a and miR126 are overexpressed in $\mathrm{CD}^{+}{ }^{+} \mathrm{T}$ cells from patients with SLE and contribute to inhibiting the expression of DNMT1 enzyme and inducing hypomethylation. Among these, miR126 modulates DNA methylation in $\mathrm{CD}^{+}{ }^{+} \mathrm{T}$ cells from lupus patients and contributes to T- and B-cell autoreactivity in SLE by directly targeting DNMT1. As a consequence of hypomethylation on promoter region, an increase in CD11a and CD70 autoimmune-related protein levels is promoted ${ }^{(12,100)}$.

Besides, Stagakis et al. (2011) analysed miR21 in PBMCs from lupus patients. Compared with healthy $\mathrm{CD}^{+}{ }^{+} \mathrm{T}$ cells, miR21 was significantly increased and correlated with SLE disease activity, showing enhanced IL10 production and CD40L expression 
Table 3. Deregulated non-coding RNAs epigenetic modifications in SLE

\begin{tabular}{|c|c|c|c|c|}
\hline ncRNAs & Cell source & Target & Action & References \\
\hline$\downarrow \mathrm{miR} 125 \mathrm{a}$ & $\begin{array}{l}\text { Monocytes } \\
\text { PBMC }\end{array}$ & $\begin{array}{l}\text { KLF13 } \\
\text { STAT3, IL13, IFN, IL16 genes }\end{array}$ & Down-regulated RANTES, immunomodulation of T cells & $(67,92,93)$ \\
\hline$\downarrow \mathrm{miR} 146 \mathrm{a}$ & SLE patients & $\begin{array}{l}\text { IRAK1, IRF5, STAT1, TRAF6, STAT3, ERK, JNK, } \\
\text { p38 MAPK }\end{array}$ & $\begin{array}{l}\text { Negative regulation of type I IFN pathway } \\
\text { Increased LN and lupus activity } \\
\text { High expression of inflammatory cytokine }\end{array}$ & (94) \\
\hline$\uparrow \operatorname{miR} 155$ & $\begin{array}{l}\text { B cells } \\
\text { PBMC }\end{array}$ & S1PR1, PU.1 & Altered secretion of IL4, IL17 and IFN- $\gamma$ and CD40 expression & (95-97) \\
\hline $\begin{array}{l}\uparrow \operatorname{miR} 21, \uparrow \operatorname{miR} 148 a, \uparrow \\
\operatorname{miR} 126\end{array}$ & $\begin{array}{l}\text { T cells from SLE patients, SLE- } \\
\text { prone mice }\end{array}$ & $\begin{array}{l}\text { DNMT1 } \\
\text { PDCD4 }\end{array}$ & Regulated CD11a, CD40L, CD70, LFA1 and DNA hypomethylation & $(98-100)$ \\
\hline$\downarrow \mathrm{miR} 142-3 \mathrm{p} / 5 \mathrm{p}$ & T cells & SAP, CD84, IL-10 & $\begin{array}{l}\text { Hyperactivity of B and T cells } \\
\text { Increased IgG production }\end{array}$ & (101) \\
\hline$\downarrow \mathrm{miR} 31$ & T cells & RhoA & Down-regulation of IL2 production and cell apoptosis & (102) \\
\hline$\uparrow \operatorname{miR} 29 a$ & T cells & Sp1 & Regulated DNMT1, CD70 and CD11a & (103) \\
\hline$\downarrow \mathrm{miR} 26 \mathrm{a}, \downarrow \mathrm{miR} 101$ & $\mathrm{~T}$ cells & EZH2 & Regulated Th2, Th17 and Tfh-related genes & (104) \\
\hline$\downarrow \mathrm{miR} 1246$ & B cells & EBF1, CD40, CD80, CD86 & B-cell activated response & (105) \\
\hline$\uparrow \mathrm{miR} 30 \mathrm{a}$ & $B$ cells & Lyn & B-cell proliferation and overactivation & (12) \\
\hline miR34a & $\begin{array}{l}\mathrm{B} \text { cells } \\
\mathrm{CD}^{+} \mathrm{T} \text { cell }\end{array}$ & Foxp3 & $\begin{array}{l}\text { Regulated B cell } \\
\text { Inhibited Treg cell differentiation }\end{array}$ & (106) \\
\hline miR150 & Mouse $B$ cells & C-Myb & Lymphocyte proliferation & (107) \\
\hline $\operatorname{miR} 181 b$ & $\mathrm{~B}$ cells & AID & $\begin{array}{l}\text { Decreased CSR } \\
\text { Altered antibody diversity }\end{array}$ & (108) \\
\hline$\downarrow$ GAS5 & $\begin{array}{l}\text { PBMC } \\
B \text { and } T \text { cells from mice }\end{array}$ & Apoptotic gene & Abolished proliferation of $\mathrm{T}$ cells and antibody production & (109) \\
\hline$\uparrow$ NEAT1 & Monocytes & Type I IFN, IL6, CXCL10 & $\begin{array}{l}\text { Activated MAPKs and type I IFN pathways } \\
\text { Increased cytokine and chemokine production, DNA hypomethylation }\end{array}$ & $(109,110)$ \\
\hline$\downarrow$ linc0949 & PBMC & IL6, TNF- $\alpha$ & $\begin{array}{l}\text { Correlated with inflammation, nephritis, SLE activity and complement } \\
\text { component C3 level }\end{array}$ & (111) \\
\hline$\downarrow$ Inc0597 & PBMC & IL6, TNF- $\alpha$ & $\begin{array}{l}\text { Increased cytokine expression } \\
\text { Activation of MAPK signalling pathway }\end{array}$ & (111) \\
\hline$\uparrow$ MALAT1 & PBMC monocytes & SIRT1 & Increased IL21 production & (109) \\
\hline$\uparrow \operatorname{lnc}-\mathrm{DC}$ & Dendritic cells & STAT3 & $\begin{array}{l}\text { Modulated T-cell activation } \\
\text { Th17 differentiation and IL2 production }\end{array}$ & (109) \\
\hline$\uparrow \operatorname{lnc} 0640$ & Plasma & Phosphatase 4 & Promoted SLE pathogenesis & (110) \\
\hline$\uparrow$ IncRNA UCA1 & T cells & - & $\begin{array}{l}\text { Correlated with C3 and anti-dsDNA antibody; promoted expression of } \\
\text { AKT and PI3K }\end{array}$ & (113) \\
\hline
\end{tabular}


through the suppression of programmed cell death protein (PDCD) 4, a selective protein inhibitor of genes involved in immune responses ${ }^{(114)}$.

In addition, miR142-3p/5p is involved significantly in pathogenesis of SLE ${ }^{(12,116)}$. Ding et al. (2012) speculated that in $\mathrm{CD}^{+} \mathrm{T}$ cells from SLE miR142-3p/5p is disrupted and acts to target signalling lymphocytic activation molecule-associated protein (SAP)-, CD84- and IL10- genes. It could be the cause of SAP, CD84 and IL10 increasing SLE-associated translation and T-cell and B-cell hyper-response ${ }^{(101)}$. Despite the fact that in lupus $\mathrm{CD}^{+} \mathrm{T}$ cells miR142-3p/5p intracellular levels are low, both were up-regulated in plasma and renal biopsies of SLE patients. This may be explained by exocytosis activity of these cells ${ }^{(117)}$.

Decreased levels of miR1246, which target early B-cell factor (EBF) 1 mRNA specifically, have been found in B cells from SLE patients, inducing hyperactivation of $\mathrm{B}$ cells through surface costimulatory molecules CD40, CD80 and CD86. Activated B cells in SLE showed a positive feedback loop, where the lower expression of miR1246 via AKT-p53 signalling induces an upregulation of EBF1 mRNA and B-cell activation ${ }^{(105)}$. On the contrary, in $\mathrm{CD}^{+} \mathrm{T}$ cells from SLE, up-regulation of miR1246 could disrupt this amplifying mechanism. These findings provide a theoretical framework towards the research of novel biological targets in SLE treatment.

Several studies using microarray analysis detected other unusual miRNAs in PBMCs from patients with active lupus. They exhibited increased expression of certain miRNAs (miR189, miR61, miR78, miR342, miR299-3p, miR198, miR298, miR574-5p, miR1308, miR638, miR7) or decreased expression of others (miR196a, miR17-5p, miR409-3p, miR141, miR383, miR112, miR184, miR186, miR197), but thus far their role in the pathogenesis of disease is unknown ${ }^{(98,100)}$

lncRNAs act more specifically in biological functions than miRNAs, suggesting a strong implication in innate immunity and inflammatory response. IncRNAs can be measured in plasma, keeping unaltered in presence of RNAses; hence, they could be excellent biomarkers ${ }^{(111)}$. Besides, some lncRNAs allow for distinguishing patients with LN from SLE patients without kidney affection.

Genetic evidence suggests that gene encoding lncRNA growth arrest-specific (GAS) 5 is implicated in SLE susceptibility. GAS5 is required for the inhibition of human T-cell proliferation by rapamycin ${ }^{(109)}$. Several authors have measured lower levels of GAS5 in $\mathrm{CD}^{+}{ }^{+} \mathrm{T}$ cells from SLE patients than from control subjects. However, the results did not show any remarkable differences regarding kidney affection between studied patients (118-120).

Furthermore, abnormal expression of IncRNA nuclear paraspeckle assembly transcript (NEAT) 1 enhances the production of cytokines and chemokines in SLE patients, especially in monocytes where it regulates some genes (CXCL9, CXCL1O, CXCL11, CCL8) related to IFN type I pathway. This fact could indicate that NEAT1 may facilitate the pathogenesis of SLE, and it may represent a novelty biomarker for diagnosis $(109,110)$.

Interestingly, some active patients of SLE disease present higher levels of linc0949, which is implicated in SLE disease activity index 2000 (SLEDAI-2K) score, nephritis and complement component $\mathrm{C}$ level and regulates IL6 and TNF- $\alpha$ production. linc0949 levels were decreased in PBMCs from lupus victims, so it could be used in monitoring of disease progression and treatment efficacy. Similarly, low expression of lnc0597 has been described in SLE PBMCs. However, it presents high levels in plasma. lnc0597 could be a regulator of IL6 and TNF- $\alpha$ cytokine expression, both of them implicated in SLE pathogenesis ${ }^{(111)}$.

Contrarily, metastasis-associated lung adenocarcinoma transcript (MALAT) 1, which regulates the sirtuin (SIRT) 1 signalling pathway and thus the production of IL21 in monocytes, was significantly increased in PBMCs and monocytes of lupus patients ${ }^{(109)}$. Considering that SLE patients exhibited higher levels of IL21 than healthy controls, we may conclude a critical role of MALAT1 in the SIRT1/IL21 pathway to lupus onset.

lnc-dendritic cell (lnc-DC) is implicated in the activation of STAT3 in dendritic cells and, subsequently, regulates T-cell activation, Th17 differentiation and IL2 production, participating in the pathogenesis of SLE. Significant differences in LN and SLE patients without nephritis have been shown. Thus, lnc-DC could be a useful biomarker to distinguish LN diagnosis in lupus patients ${ }^{(109)}$.

\section{Epigenetic modifications as potential biomarkers and therapeutic targets}

A comprehensive understanding of epigenetic approaches to autoimmune/inflammatory disease is necessary to predict individual disease outcomes and the introduction of effective, target-directed and tolerable therapies. Epigenetic events may, at least partially, explain inter-individual differences. In this line, epigenetic biomarkers are proving useful to verify molecular aberrations and environmental factors. Also, novel targets for individualised therapeutic interventions are making possible an advance in prevention, diagnosis and treatment. Nevertheless, epigenetic therapy needs further study.

Nowadays, drugs targeting epigenome alterations are focused on molecular inhibitors of DNMTs (DNMTi) and HDACs (HDACi).

In fact, several DNMTi have been developed, mainly as anticancer agents. These epigenetic modulators cause cell cycle and growth arrest, differentiation and apoptosis. Validation of cotherapies using these agents with cytotoxic drugs or radiotherapy could be crucial because the use of DNMTi offers improved access to cytotoxic agents or radiation for targeting DNA-protein complex. Therefore, there is a promising interest in the use of DNMTi as potential chemo- or radiation sensitisers to increase clinical response ${ }^{(121)}$. Generically, DNMTi may be classified into two main classes, depending on their mode of action: nucleoside analogues and non-nucleoside analogues.

Firstly, nucleoside analogues consist of a cytosine ring connected to ribose or deoxyribose, which may integrate into DNA or RNA through replacement of cytosine units. Once incorporated into DNA and bonded to it covalently, they inhibit DNMTs activity ${ }^{(122)}$. To date, the most well-characterised nucleoside analogues are 5-azacytidine and 5'-aza-2'-deoxycytidine. Both of them were approved by the Food and Drug Administration (FDA) to treat myelodysplastic disorders ${ }^{(123)}$, 
so most current preclinical and clinical trials evaluating functional effects and therapeutics targets are focused on cancer $(122,124)$. The treatment of human or mouse $\mathrm{CD}^{+} \mathrm{T}$ cells with these DNMTis induces or aggravates lupus-like disease, triggering T-cell autoreactivity and providing evidence of the implication of DNA methylation in autoimmunity ${ }^{(58)}$. Richardson treated $\mathrm{CD}^{+} \mathrm{T}$ cells from healthy mice with 5-azacytidine, and then injected 5-azacytidine into identical animals. Mice receiving 5azacytidine-treated cells expressed signs, anti-nuclear antibodies and complex glomerulonephritis closely related to human lupus (125). Interestingly, several studies have demonstrated that the treatment of natural T cells with 5-azacytidine induced overexpression of different genes susceptible to methylation, as a consequence of DNMT inhibition. The genes identified were: the TB cell co-stimulatory molecules CD70 and CD40L, the T-cell autoreactivity molecule CD11a, and the protein that integrates lethal pores into cell membrane perforin. All of them are hypomethylated and overexpressed in $\mathrm{T}$ cells from lupus patients (58,126-128). Treatment with 5-azacytidine has been used amply as drug-induced lupus, and it has enabled confirmation of the pattern of DNA methylation in SLE.

Additionally, other cytidine analogues have been developed to improve the properties of azanucleoside agents. Zebularine is a deoxycytidine derivative that lacks an amino group in position four of the pyrimidine ring ${ }^{(129)}$. Its oral bioavailability and capacity to reactivate a silenced gene by oral administration have been well established ${ }^{(130)}$.

Another known DNMTi, 5-fluoro-2'-deoxycytidine, is a fluoropyrimidine nucleoside analogue that may bind covalently to DNMTs and form a suicide complex ${ }^{(131)}$; and 5,6-dihydro-5-azacytidine (DHAC) may be incorporated into RNA, inhibiting its synthesis and DNA methylation in human cell lines ${ }^{(124)}$. SGI110 (guadecitabine) has been shown to be effective in DNA methylation inhibition in both in vitro and in vivo studies. Also, this second-generation drug seems to act as an immune modulator ${ }^{(132)}$. To improve 5-azacytidine, CP-400 was designed independently to the nucleoside transport system and showed more efficacy. Gemcitabine, the most-used treatment in cancer, is an anti-metabolite that acts with two active metabolites, inhibiting ribonucleoside reductase and/or in DNA replication supplanting a cytosine unit ${ }^{(122)}$.

Secondly, the non-nucleoside analogue group includes those compounds that bind to DNMTs covalently, without a previous interaction within DNA strand ${ }^{(122)}$. Some DNMTis of this group are procaine, procainamide, hydralazine, MG98 and RG108, among others. Procaine and procainamide act by inhibiting DNMTs, but they are also drugs usually employed as local anaesthetics and anti-arrhythmics, respectively. Nonetheless, procainamide has exhibited a more selective action on DNMT1 than on DNMT3a and DNMT3b ${ }^{(133)}$. IM25 was derived from procainamide, within an improved toxic profile ${ }^{(122)}$.

Hydralazine was primarily used to treat high blood pressure. It forms strong hydrogen bonds with arginine and glutamic residues of DNMT1 ${ }^{(123)}$. Like azanucleosides, most current studies about functional effects and therapeutics targets of non-nucleosides are focused on anti-cancer therapy. However, the treatment with procainamide or hydralazine disrupted genomewide epigenetics and induced lupus-like disease. These drugs cause DNA hypomethylation in T cells and, thus, increased expression of LFA1, a molecule involved in T-cell activation, inducing autoreactivity. Similar murine studies have further confirmed that procainamide and hydralazine may induce overexpression of lupus-associated genes (CD70, CD4OL, CD11a), considering them as SLE-induced drugs ${ }^{(58,126-128)}$.

Complementarily, some non-nucleoside analogues exert precise DNMT inhibition. Nanaomycin A inhibits DNMT3b selectively; MG98, a second-generation short antisense nucleoside, acts on DNMT1 mRNA and down-regulates DNMT1 expression; and RG108 inhibits DNMT1 at catalytic domain. These secondgeneration drugs present a less cytotoxic profile ${ }^{(122)}$.

Other modifier drugs of DNA methylation target on DNMTs are methotrexate, an immune-suppressant used in rheumatic diseases, and cyclophosphamide, an antineoplastic drug (50). Methotrexate can deplete SAM levels, the substrate of DNMT, thus inhibiting it indirectly. On the other hand, cyclophosphamide induces DNMT1 activity, implementing DNA methylation. These epigenetic actions may provide a better understanding of the efficacy of treating SLE patients with methotrexate or cyclophosphamide ${ }^{(50)}$.

The concept of precise modulation of methylated DNA in Tcell subsets has transformative potential in the treatment of ADs and beyond, but the global effects of DNMTis in different cell types render systemic treatment outcomes unpredictable, disturbing unaffected genes and deregulating them (134). Unfortunately, SLE patients exhibit hypomethylation of genes, and only a few of them are hypermethylated; thus, the treatment with DNMTis reverting DNA hypomethylation is not an option.

Contrarily, different studies have reported HDACis improved autoimmune and inflammatory diseases (135,137). Accordingly, two HDACis have attracted special attention: trichostatin A (TSA) and suberoylanilide hydroxamic acid (SAHA or vorinostat), improving proteinuria, spleen weight and glomerulonephritis. Nanomolar concentrations of these have shown specific and reversible inhibition of HDACs. The effectiveness of TSA and SAHA on SLE disease has been tested in lupus murine models or in vitro, but no data are available yet about the restoration of histone acetylation and treatment in lupus patients. Daily TSA administration inhibited the production of inflammatory mediators in spleen and kidney of NBZ/W mice, leading to increased functionality of Treg cells associated with HDC inhibition ${ }^{(138)}$. In this line, Garcia et al. (2005) corroborated in MRLlpr/lpr mice a correction of site-specific hypoacetylated after TSA treatment ${ }^{(83)}$. Mishra et al. (2003) reported the ability of TSA and SAHA in MRL-lpr/lpr mice. These inhibitors decreased levels of autoantibodies and proinflammatory cytokines such as IFN- $\boldsymbol{\gamma}$, IL12, IL6 and IL10 mRNA, improving kidney and spleen affection. These inhibitors together were associated with HDACi efficacy to restore acetylation on $\mathrm{H} 3$ and $\mathrm{H} 4{ }^{(139)}$. Besides, these authors treated T cells from SLE patients with TSA, and significant down-regulation of CD154 and IL10 and up-regulation of IFN- $\gamma$ were observed. Consequently, the capacity of TSA to interfere in inflammatory response through regulation of the CD40-CD154 axis (related to diverse immune system pathways), IL10 and IFN$\gamma$ expression supports its potential as a therapeutic agent to SLE ${ }^{(140)}$. 
ACY-738, a specific HDAC6 inhibitor, increased splenic Tregs and decreased Th17 cells in NZB/W mice, related to decreased serum anti-dsDNA levels. Moreover, ACY-738 improved the phenotype of SLE by inhibiting the production of IL6, IL10 and TGF- $\beta$, and deposition of C3 and IgG in glomeruli, reducing LN ${ }^{(140)}$. CKD-506, another inhibitor of HDAC6, enhanced survival rate and decreased proteinuria, kidney inflammation and glomerular infiltration of $\operatorname{IgG}$ and $\mathrm{C} 3$ in NZB/W F1 mice. Furthermore, CKD-506 reduced levels of inflammatory cytokines in serum and kidney ${ }^{(142)}$. Recent studies showed that ITF2357 (givinostat), an inhibitor of class I and II HDACs that is used mainly in juvenile idiopathic arthritis, increased Treg cells and Foxp3 acetylation and, thus, inhibited autoantibody and proinflammatory cytokine production in NZB/W mice. Experiments in animals showed SLE reduced serum and urine biomarkers ${ }^{(143)}$.

Based on these studies, it has been suggested that HDACi may be a promising new therapy for SLE. Nevertheless, the clinical effects of HDACi in lupus patients have not been demonstrated yet. Conversely, histone-modifying drugs have been used for epilepsy (valproic acid) and oncology (vorinostat, romidepsin) therapies ${ }^{(6,144)}$. Additionally, the FDA approved vorinostat for the treatment of cutaneous T-cell lymphoma in 2006 $(145,146)$, used in monotherapy or in combination with other drugs (147-149). On the other hand, givinostat improved juvenile idiopathic arthritis ${ }^{(150)}$ and reduced muscle fibrosis in Duchenne muscular dystrophy, showing an excellent safety profile ${ }^{(151)}$.

In short, epigenetic markers and immune-associated activity may be used as novel therapeutic targets and biomarkers, supplying possible alternatives to clinical treatment in SLE. Future research and investigations about epigenome in specific cell types and organs are needed to support the mechanism of action of these DNMTi and HDACi 'epidrugs' in the disease and their future applications in SLE. This aspect should be studied in depth, evaluating the efficacy of therapy within these agents, alone or in combination with existing therapies in clinical trials of patients with lupus disorders, which complement the results obtained in recently published preclinical studies.

\section{Diet, epigenetic and SLE linkage}

The pathogenic process of ADs is considered a complicated and complex challenging question. Genetic predisposition and environmental factors, such as nutrition, infection, pollution or UV exposure, can cause autoimmunity and are implicated in the pathogenesis, although how much of each is not well known yet. Nutrition and dietary habits are one of the most accessible external factors, with diet being a possible tool to act on the disease onset. Generally, it has been recognised that feeding habits, such as calorie restriction or supplementation with macronutrients (fibre, unsaturated fatty acids or specific bioactive compounds ${ }^{(152)}$ ), may influence development and predisposition of pathologies, especially ADs ${ }^{(153)}$. A growing number preclinical and clinical studies have evidenced the relation of dietary components and patterns with the immune response ${ }^{(154)}$. A clear example of this is the discordance in the incidence of immunemediated diseases in Western countries. In fact, the
Mediterranean diet might support an improvement in diseases related to the immune system, inflammation or oxidative stress, confirmed in RA, SLE, cardiovascular disease (CVD), cancer and neurodegenerative disease patients, among others ${ }^{(155-159)}$. This diet emphasises vegetables, fruits, nuts, fish and olive oil (OO) as a main fat source.

Focusing on SLE disorders, there has been a growing body of preclinical and clinical literature describing the control of lupus disease by dietary interventions ${ }^{(160)}$. A high-quality diet is of notable importance since these patients used to be affected with vitamin and mineral deficiencies, anaemia or high CVD susceptibility ${ }^{(10)}$. A balanced diet and its nutrients exhibit antioxidant, anti-inflammatory and immunomodulatory properties (10). Accordingly, a nutritional therapy based on carbohydrate and protein restriction, and vitamin (A, B, C, D and E) and omega-3 supplementation with adequate fibre and sodium consumption, enables a reduction in the severity, or prevention, of disease ${ }^{(10,154,158-162)}$. In spite of multiple studies suggesting the beneficial properties of nutritional therapy ${ }^{(161,162)}$, more clinical trials are needed and further research is required.

In this respect, a cross-relation between $\mathrm{ADs}$, diet and epigenetics may exist. Several authors have shown that certain early diet habits may lead to metabolic and physiology changes through epigenetic altered pattern, defining susceptibility to chronic pathologies with the passage of time ${ }^{(153,163,164)}$. Based on diet restriction and following specific eating habits, such as Mediterranean diet or consumption of certain nutrients, they have shown their implication for modulation of DNA methylation, histone patterns or ncRNA expression ${ }^{(163,165-168)}$. Even following specific pregnancy-feeding guidelines seems to play a key role in the epigenetic profile of embryo ${ }^{(153)}$.

Diet is an essential player in homeostasis of epigenetic marks, making it a top influencer for SLE development ${ }^{(127)}$. To date, there are some studies about nutrients' effect on HDAC and HAT activity or miRNA expression, but diet's influence on DNA methylation is better established. There are two main mechanisms that alter DNA methylation: (i) availability of methyl donors, and (ii) disruption of DNMT1 activity ${ }^{(163)}$. The most widely investigated of them is the influence of nutrients on methyl group supply for one-carbon metabolism.

Partly, this may be due to levels of SAM, a methyl donor, dependent on dietary micronutrients, such as folate, zinc, methionine, choline, and B6 and B12 vitamins, and oxidative stressors and age, which may decrease DNMT1 activity. In SLE patients, high oxidative response and sensitivity to diets deficient in SAM donors has been observed. For this reason, the maintenance of balance between DNMT1 and SAM levels is a key point to avoid SLE flares and onset ${ }^{(127,169)}$. Accordingly, Strickland and colleagues observed that dietary micronutrients which are implicated in methylation process may affect genes through epigenetic mechanisms in correlation with the severity of disease ${ }^{(170)}$. A transgenic lupus model with inducible ERK pathway signalling defect was bred onto lupus-resistant (C57BL/6) and lupus-susceptible (C57BL/6xSJL) mouse strains. These mice express a dominant-negative MEK uniquely in $\mathrm{CD} 2^{+}$cells when doxycycline, a DNMT1 level regulator, is administered in their drinking-water. Both mouse groups that were fed a diet with low levels of methyl-related nutrients (choline and methionine) 
showed high renal damage and developed haematuria, while mice fed with a diet supplemented with high levels of methyl donors reduced the development of kidney disease. Taken together, the authors concluded that dietary micronutrients can contribute to lupus susceptibility and severity through genetic/epigenetic interactions that affect DNA methylation.

Additionally, SLE patients present decreased levels of vitamins, methionine and other methyl-donors in comparison with healthy individuals. Nevertheless, diet supplemented with vitamins (A, B6, C, D or E) resulted in improvement of flares and symptoms of SLE ${ }^{(10)}$. Ray et al. (2018) hypothesised that expression of genes susceptible to DNA methylation in T cells from SLE patients may be more prevalent in low-micronutrient conditions than in healthy $\mathrm{T}$ cells. They cultured $\mathrm{CD} 4^{+} \mathrm{T}$ cells from lupus patients PHA-stimulated in culture media with normal or low levels of B6 and B12 vitamins, methionine, folate and choline, and then measured expression of $\mathrm{CD} 70$, perforin and KIR ${ }^{(171)}$. It should be noted that KIR, perforin and $C D 70$ genes are usually hypermethylated and overexpressed in SLE ${ }^{(58,125-128)}$. The authors observed that $\mathrm{CD}^{+} \mathrm{T}$ cells from SLE patients cultured in low levels of supplements exhibited an increase in these methylation-sensitive genes ${ }^{(171)}$. In conclusion, SLE patients may pay attention to their nutrition to avoid low levels of methyl donors and DNMT activity, preventing lupus flares and onsets, especially older people with more diet deficiencies.

A large number of articles have reported independently that some bioactive compounds consumed in diet exert beneficial properties on SLE, and these same micronutrients act via epigenetic modulation ${ }^{(10,172,173)}$, although most of them have been established in cancer. Taking these properties into consideration, we could analyse these studies in order to clarify the cross-relation among the consumption of these nutraceuticals, the improvement in SLE disease profile and their effects on epigenetic machinery (Table 4). Some of these dietary bioactive compounds could be curcumin, epigallocatechin gallate (EGCG), resveratrol, genistein, indole-3-carbinol (I3C) or OO.

Curcumin, a polyphenol from the golden spice turmeric, inhibited cell proliferation and differentiation and ameliorated the immune response of Th1 through IFN- $\gamma$ inhibition. Besides, this polyphenol reduced Th17 cell response, inhibiting the expression of relevant proinflammatory cytokines, and modulated Th17/Treg cell balance in $\mathrm{CD}^{+}$from SLE patients, exhibiting therapeutic profile to this $\mathrm{AD}^{(174-176)}$. In experimental animal studies, curcumin-supplemented diet ameliorated renal damage and controlled autoantibody and cytokine production on lupus onset ${ }^{66,176,177)}$. Similar effects were observed in clinical trials using curcumin-supplemented diet or curcumin-treated $\mathrm{T}$ cells from SLE patients, regulating Th17/Treg balance of $\mathrm{CD}^{+}$

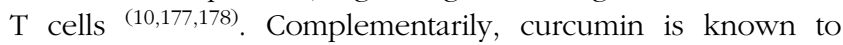
decrease HAT activity at $\mathrm{H} 3 \mathrm{ac}$ of $I L 6$ promoter, inhibiting the release of IL6 and TNF- $\alpha{ }^{(180)}$. Balasubramanyam and colleagues (2004) postulated that curcumin was the first known p300 specific natural HAT inhibitor in transcription ${ }^{(181)}$. Moreover, daily intake of curcumin decreased miR21 and miR155 levels and suppressed DNMT1, DNMT3a and DNMT3b expressions ${ }^{(180)}$.

In this line, different in vitro and in vivo studies support the modulation action of the green-tea polyphenol ECGC on NF-kB, nucleoside binding domain (NOD)-like receptors (NLRP) 3, 


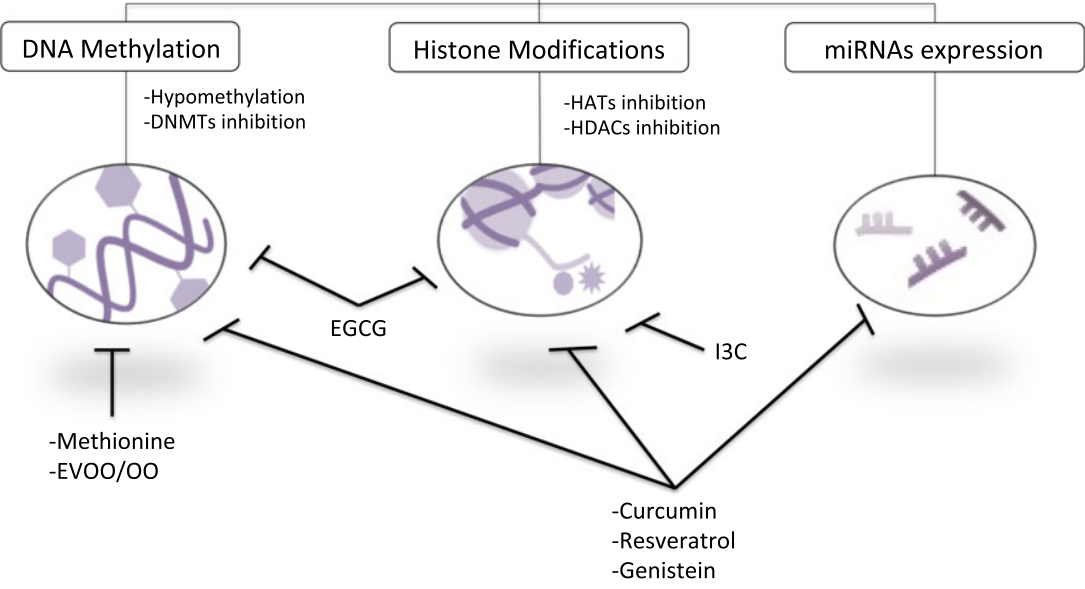

Fig. 2. Schematic representation linking key epigenetic mechanism and bioactive compounds consumed in diet. Several micronutrients exhibited regulatory properties on epigenetics through hypomethylation of DNA, DNMT inhibition and/or regulation of HATs, HDACs and miRNAs. EGCG, epigallocatechin gallate; EVOO/OO, extra virgin olive oil/olive oil; I3C, indole-3-carbinol.

nuclear factor erythroid-derived (Nrf) 2 and T-cell activation. Overall, EGCG controls inflammation and prevents renal function impairment. In this line, several in vivo studies showed depletion of progression in lupus-like syndrome, including glomerulonephritis and autoantibody production in ECGC-fed mice (10,182-184). With regard to epigenetics, EGCG decreased HDACs and HAT class I activity that affected NF-kB, IL6 expression and inflammatory response ${ }^{(185)}$, but also, EGCG inhibited histone methyltransferase EZH2, which adds a methyl group to H3K27. Moreover, this green-tea polyphenol inhibited DNA methylation through an interaction with DNMT1. It was able to form four hydrogen bounds on the catalytic centre of DNMT1, rejecting the entrance of cytosine residue ${ }^{(186)}$. Also, DNMT3a and DNMT3b were inhibited in an in vivo study with EGCG-treated mice ${ }^{(187)}$. Complementarily, antioxidant properties of green tea could be explained by restoring expression of antioxidant enzymes, as glutathione $S$-transferase P (GSTP) 1 by inducing demethylation and DNMT inhibition ${ }^{(123)}$.

Resveratrol, a polyphenol present in tomato, peanuts or skin of red grapes, showed protective effects in lupus disorders, and supported its ability to regulate inflammatory genes and transcription factors such as STAT3, NF-kB or cyclooxygenase (COX) 2, implicated in SLE disease ${ }^{(188,189)}$. Consequently, in oxidative stress and inflammatory response, resveratrol treatment decreased the expression and activity of DNMT3a and SIRT1, ameliorating harmful conditions ${ }^{(190)}$. In addition, resveratrol treatment in human THP-1 macrophages restored levels of pro-inflammatory cytokines through miR-Let7A overexpression ${ }^{(191)}$, and controlled miR21 levels, down-regulating NF-kB, TNF$\alpha$, IL1 $\beta$ and IL6 ${ }^{(123)}$.

I3C is abundant in cruciferous vegetable such as broccoli, cabbage or cauliflower. In NZB/w F1 mice fed with a I3C-supplemented diet, proteinuria and renal affections were decreased and survival of animals was increased ${ }^{(192)}$. These data confirmed a beneficial effect of dietary I3C in experimental SLE.
Recently, Eghbalpour et al. (2020) investigated the effect of I3C on transcriptional profiling of macrophage-derived monocytes (MDMs) from SLE patients in four stages of the woundhealing process. The results showed that treatment with I3C could modulate STAT1, THBS1 and ATP2A3 gene expression involved in wound healing in SLE cases and healthy controls (193). Additionally, I3C counteracted the effects of staphylococcal enterotoxin B (SEB), a superantigen inductor of inflammation and immune cell activation, in SEB-stimulated T cells. This indole re-established pro-inflammatory cytokines levels and cellular infiltration, inhibited HDAC class I and decreased miR31 production. Busbee and colleagues suggested that the regulatory epigenetic action associated with $\mathrm{I} 3 \mathrm{C}$ was the reason for its immuneinflammatory regulation capacity ${ }^{(194,195)}$.

The isoflavone genistein that is present in soybeans is well known for its antioxidant effects. Genistein improved the severity of disease and regulated autoantibody production, proteinuria and renal pathology in lupus patients ${ }^{(10)}$. Recently, Li et al. (2019) reported that genistein may recover epigenetic aberrations of Klotho (kidney anti-aging and fibrosis-suppressing protein) in a mouse kidney disease incurred by unilateral ureteral occlusion. The authors used genistein-treated human kidney tubular cells (HK2) and C57BL/6 mouse kidney lysates. Genistein inhibited DNMT1, DNMT3a and DNMT3b and also decreased histone acetylation, alleviating renal fibrosis by Klotho restoration (196). Additionally, levels of miR155 were down-regulated in MDA-MB-435 and Hs578t cancer cells treated with genistein ${ }^{(197)}$. The potential effectiveness of genistein in the restoration of epigenome alterations suggests it is an interesting dietary supplement in prophylaxis and treatment of several ADs and cancer.

The beneficial properties of OO in SLE have been described widely, particularly extra virgin olive oil (EVOO). Aparicio-Soto and colleagues have demonstrated that SLE-induced mice fed with EVOO-supplemented diet presented lower renal 
incidence and inflammatory mediators, such as matrix metalloprotease (MMP) 3, prostaglandin ( $\mathrm{PG}$ ) $\mathrm{E}_{2}$, pro-inflammatory cytokines, Nrf-2/haem oxygenase (HO) 1, MAPKs and NF-kB signalling pathways ${ }^{(198)}$. These authors also reported that polyphenolic fraction of EVOO modulated cytokine production, attenuating T-cell activation using PBMC from lupus patients ${ }^{(199)}$. In terms of DNA methylation, EVOO induced changes in the expression of several inflammatory-related genes in peripheral leucocytes from patients fed a Mediterranean diet ${ }^{(200)}$. Moreover, OO exerted demethylating activity and inhibited DNMT1 ${ }^{(201)}$.

In summary, dietary interventions could modify the epigenetic profile, with numerous studies consolidating this affirmation (Fig. 2). Although several publications report correlating changes in epigenetic-specific alteration in some genes and its expression in response to dietary bioactive compounds, to date, few of them have investigated both influence on lupus and the functional consequences of modifying nutrition habits.

\section{Conclusion}

There is growing evidence for the implication of environmental factors, such as nutrition, lifestyle or UV exposure, that orchestrate epigenetic changes in predisposed subjects, contributing to modulation of SLE onset. Generally, global losses of DNA methylation and $\mathrm{H} 3$ and $\mathrm{H} 4$ histone deacetylation have been identified in lupus disorder. Despite the fact that more accurate and revealing preclinical and clinical works are required for understanding the pathogenic mechanism contributing to SLE, epigenome patterns have been proposed as novel approaches to SLE therapy.

Accordingly, DNA methylation and histone modification have been postulated as key targets that could be employed in the development of individual and precise therapies with lower or no side effects. Particularly, recent studies have suggested the testing of some 'epidrugs', whose mechanism of action is based on DNMT or HDAC inhibition, underscoring the capacity of these drugs to modulate target gene expression defined in SLE.

In fact, the measurement of ncRNAs levels in serum or certain organs has been established as useful diagnosis tools. Indeed, significant differences in several miRNAs' levels were observed between lupus patients and normal controls, or even in lupus patients with kidney affection compared with those without kidney damage. These revealing facts suggest miRNAs as new strategies for diagnosis and therapeutic targets of lupus.

Improvement of disease associated with some micronutrients has been widely demonstrated; notwithstanding, little is known about their relation with epigenetic alteration in SLE. Although studies are not conclusive and further research is required, it seems to be clear that diet supplemented with certain bioactive compounds could be effective in preventing or avoiding aberrant modifications in epigenome to improve SLE onset. Therefore, the combined use of epigenetic bioactive compounds with therapeutic drugs could be of interest because of the possible synergistic effects that may be observed in the treatment of disease.
Mainly dietary bioactive compounds have been studied within cancer mice models and only a few preclinical trials, so emergence studies in SLE and immune-inflammatory disorders are required for a better understanding. Nonetheless, the effects of the dietary bioactive compound on the epigenome, a socalled epigenetic diet, could offer an approach in prevention, therapy and diagnosis of diseases in the future.

\section{Financial Support}

The authors acknowledge the financial support by the research grant from the Ministerio de Economía y Competitividad of Spain (AG2017-89342-P). T.M. thanks the Postgraduate Program of PIF fellowship and financial sponsorship from VI Plan Propio de Investigación y Transferencia de la Universidad de Sevilla. R.M. gratefully acknowledges the FPU fellowship from Ministerio de Educación y Cultura of Spain.

\section{Conflicts of Interest}

The authors declare no conflict of interest.

\section{Authorship}

C.A.-d.-1.-L. and T.M. conceived the idea. M.L.C., R.M.-G., T.M. and C.A.-d.-1.-L. reviewed the published literature and wrote the first draft of the manuscript. C.A.-d.-1.-L. and T.M. revised and edited the final manuscript. All authors contributed and approved the published version of the manuscript.

\section{References}

1. Mazzone R, Zwergel C, Artico M, et al. (2019) The emerging role of epigenetics in human autoimmune disorders. Clin Epigenetics 11, 34, 1-15.

2. Costenbader KH, Gay S, Alarcón-Riquelme ME, et al. (2012) Genes epigenetic regulation and environmental factors: which is the most relevant in developing autoimmune diseases? Autoimmun Rev 11, 8, 604-609.

3. Aslani S, Mahmoudi M, Karami J, et al. (2016) Epigenetic alterations underlying autoimmune diseases. Autoimmunity 49, 2 , 69-83.

4. Foma AM, Aslani S, Karami J, et al. (2017) Epigenetic involvement in etiopathogenesis and implications in treatment of systemic lupus erythematous. I Inflamm Res 66, 1057-1073.

5. Araki Y, Mimura T (2017) The histone modification code in the pathogenesis of autoimmune diseases. Mediators Inflamm 2017, 1-12.

6. Hedrich CM (2017) Epigenetics in SLE. Curr Rheumatol Rep 19, $58,1-13$.

7. Meda F, Folci M, Baccarelli A, et al. (2011) The epigenetics of autoimmunity. Cell Mol Immunol 8, 226-236.

8. Jeffries MA and Sawalha AM (2011) Epigenetics in systemic lupus erythematosus: leading the way for specific therapeutic agents. Int J Clin Rheumtol 6 (4), 423-439. https://doi.org/10. 2217/ijr.11.32.

9. Ngalamika O, Zhang H, Yin H, et al. (2012) Epigenetics, autoimmunity and hematologic malignancies: a comprehensive review. J Autoimmun 39, 451-465. 
10. Aparicio-Soto M, Sánchez-Hidalgo M \& Alarcón-de-la-Lastra C (2017) An update on diet and nutritional factors in systemic lupus erythematosus management. Nutr Res Rev 30, 118-137.

11. Zhan Y, Guo Y \& Lu Q (2016) Aberrant epigenetic regulation in the pathogenesis of systemic lupus erythematosus and its implication in precision medicine. Cytogenet Genome Res 149, 141-155.

12. Honarpisheh M, Köhler P, von Rauchhaupt E, et al. (2018) The involvement of microRNAs in modulation of innate and adaptive immunity in systemic lupus erythematosus and lupus nephritis. J Immunol Res 2018, 1-15.

13. Vina ER, Utset TO, Hannon MJ, et al. (2014) Racial differences in treatment preferences among lupus patients: a two-site study. Clin Exp Rheumatol 32, 680-688.

14. Mina R \& Brunner HI (2013) Update on differences between childhood-onset and adult-onset systemic lupus erythematosus. Arthritis Res Ther 15, 218.

15. Deapen D, Escalante A, Weinrib I, et al. (1992) A revised estimate of twin concordance in systemic lupus erythematosus. Arthritis Rheumm 35, 311-318.

16. Javierre BM, Fernandez AF, Richter J, et al. (2010) Changes in the pattern of DNA methylation associate with twin discordance in systemic lupus erythematosus. Genome Res $\mathbf{2 0}$ (2), 170-179.

17. Syrett CM, Paneru B, Sandoval-heglund D, et al. (2019) Altered $\mathrm{X}$-chromosome inactivation in T cells may promote sex-biased autoimmune diseases. JCI Insight 4(7), e126751.

18. Lu Q, Wu A, Tesmer L, et al. (2007) Demethylation of CD40LG on the inactive $\mathrm{X}$ in $\mathrm{T}$ cells from women with lupus. JImmunol 179(9), 6352-6358.

19. Zhou Y and Lu Q (2008) DNA methylation in T cells from idiopathic lupus and drug-induced lupus patients. Autoimmun Rev 7(5), 376-383. https://doi.org/10.1016/j.autrev.2008.03. 003.

20. Zhao M, Sun Y, Gao F, et al. (2010) Epigenetics and SLE: RFX1 downregulation causes CD11a and CD70 overexpression by altering epigenetic modifications in lupus CD4+ T cells. $J$ Autoimmun 35 (1), 58-69.

21. Luo Y, Zhao M, Lu Q (2010) Demethylation of promoter regulatory elements contributes to CD70 overexpression in CD4+ T cells from patients with subacute cutaneous lupus erythematosus: experimental dermatology. Clin Exp Dermatol 35 (4), 425-430. https://doi.org/10.1111/j.1365-2230.2009.03611.x.

22. Mi XB, Zeng FQ (2008) Hypomethylation of interleukin- 4 and -6 promoters in $\mathrm{T}$ cells from systemic lupus erythematosus patients. Acta Pharmacol Sin 29 (1), 105-112. https://doi. org/10.1111/j.1745-7254.2008.00739.x

23. Hedrich CM, Rauen T, Kis-Toth K, et al. (2012) CAMP-responsive element modulator $\alpha(\mathrm{CREM} \alpha)$ suppresses IL-17F protein expression in $\mathrm{T}$ lymphocytes from patients with systemic lupus erythematosus (SLE). J Biol Chem 287 (7), 47154725. https://doi.org/10.1074/jbc.M111.323261.

24. Hedrich CM, Crispin JC, Rauen T, et al. (2012) CAMP response element modulator $\alpha$ controls IL2 and IL17A expression during CD4 lineage commitment and subset distribution in lupus. Proc Natl Acad Sci U S A 109 (41), 16606-16611. https://doi. org/10.1073/pnas.1210129109.

25. Zhao M, Tan Y, Peng Q, et al. (2018) IL-6/STAT3 pathway induced deficiency of RFX1 contributes to Th17-dependent autoimmune diseases via epigenetic regulation. Nat Commun 9, 583.

26. Zhao M, Zhou Y, Zhu B, et al. (2016) IFI44L promoter methylation as a blood biomarker for systemic lupus erythematosus. Ann Rheum Dis 75 (11), 1998-2006. https://doi.org/10.1136/ annrheumdis-2015-208410.
27. Zhao M, Wang J, Liao W, et al. (2016) Increased 5-hydroxymethylcytosine in CD4+ T cells in systemic lupus erythematosus. J Autoimmun 69,64-73. https://doi.org/10.1016/j.jaut.2016. 03.001.

28. Gensterblum E, Renauer P, Coit P, et al. (2018) CD $4+$ CD28+KIR + CD11a Hi T cells correlate with disease activity and are characterized by a pro-inflammatory epigenetic and transcriptional profile in lupus patients. $J$ Autoimmun 48109, 19-28. https://doi.org/10.1016/j.jaut. 2017.09.011.

29. Basu D, Liu Y, Yarlagadda S, et al. (2005) Stimulatory and inhibitory killer immunoglobulin-like receptor molecules are expressed and functional on lupus T cells. Bone $\mathbf{2 3}$ (1), 1-7. https://doi.org/10.4049/jimmunol.0900034.Stimulatory.

30. Sunahori K, Juang Y-T, Kyttaris VC, et al. (2011) Promoter hypomethylation results in increased expression of protein phosphatase $2 \mathrm{~A}$ in $\mathrm{T}$ cells from patients with systemic lupus erythematosus. J Immunol Ress 186, 4508-4517.

31. Deng C, Kaplan MJ, Yang J, et al. (2001) Decreased Ras-mitogen-activated protein kinase signaling may cause DNA hypomethylation in T lymphocytes from lupus patients. Arthritis Rheum 44 (2), 397-407. https://doi.org/10.1002/15290131(200102)44:2<397::AID-ANR59>3.0.CO,2-N.

32. Li Y, Zhao M, Yin H, et al. (2010) Overexpression of the growth arrest and DNA damage-induced $45 \alpha$ gene contributes to autoimmunity by promoting DNA demethylation in lupus T cells. Arthritis Rheum 62, 1438-1447.

33. Li Y, Huang C, Zhao M, et al. (2013) A possible role of HMGB1 in DNA demethylation in CD4 + T cells from patients with systemic lupus erythematosus. Clin Dev Immunol 2013, 206298.

34. Kaplan JM, Lu Q, Wu A, et al. (2004) Lupus T cells + overexpression in $\mathrm{CD} 4$ elements contributes to perforin demethylation of promoter regulatory. J Immunol 172, 3652-3661.

35. Zhou Y, Yuan J, Pan Y, et al. (2009) T cell CD40LG gene expression and the production of IgG by autologous $\mathrm{B}$ cells in systemic lupus erythematosus. Clin Immunol 132, 362-370.

36. Zhao M, Tang J, Gao F, et al. (2010) Hypomethylation of IL10 and IL13 promoters in CD4 + T cells of patients with systemic lupus erythematosus. J Biomed Biotechnol 2010, 931018.

37. Garaud S, Le Dantec C, Jousse-Joulin S, et al. (2009) IL-6 modulates CD 5 expression in B cells from patients with lupus by regulating DNA methylation 1.J Immunol 182, 5623-5632.

38. Chung SA, Nititham J, Elboudwarej E, et al. (2015) Genomewide assessment of differential DNA methylation associated with autoantibody production in systemic lupus erythematosus. PLoS One 10(7), e0129813.

39. Zhu H, Mi W, Luo H, et al. (2016) Whole-genome transcription and DNA methylation analysis of peripheral blood mononuclear cells identified aberrant gene regulation pathways in systemic lupus erythematosus. Arthritis Res Ther 18(1), 162.

40. Absher DM, Li X, Waite LL, et al. (2013) Genome-wide DNA methylation analysis of systemic lupus erythematosus reveals persistent hypomethylation of interferon genes and compositional changes to CD4+ T-cell populations. PLoS Genet 9 (8), e1003678.

41. Liang J, Zhu XH, Qin HH, et al. (2015) A correlation study on the effects of DNMT1 on methylation levels in CD4+ T cells of SLE patients. Int J Clin Exp Med 8(10), 19701.

42. Hong KM, Kim HK, Park SY, et al. (2017) CD3Z hypermethylation is associated with severe clinical manifestations in systemic lupus erythematosus and reduces CD3f-chain expression in $\mathrm{T}$ cells. Rheumatology 56(3), 467-476. https://doi.org/10.1158/1535-7163.MCT-09-1202. 
43. Long H, Yin H, Wang L, et al. (2016) The critical role of epigenetics in systemic lupus erythematosus and autoimmunity. $J$ Autoimm 74, 118-138.

44. Sawalha AH, Jeffries M, Webb R, et al. (2008) Defective T-cell ERK signaling induces interferon-regulated gene expression and over-expression of methylation-sensitive genes similar to lupus patients. Genes Immun 9, 368e 378 .

45. Strickland FM, Li Y, Johnson K, et al. (2015) CD4(p) T cells epigenetically modified by oxidative stress cause lupus-like autoimmunity in mice. J Autoimmun 62, 75e80.

46. Gorelik G, Sawalha AH, Patel D, et al. (2015) T cell PKCס kinase inactivation induces lupus-like autoimmunity in mice. Clin Immunol 158, 193e203.

47. Sunahori K, Nagpal K, Hedrich CM, et al. (2013) The catalytic subunit of protein phosphatase 2A (PP2Ac) promotes DNA hypomethylation by suppressing the phosphorylated mitogen-activated protein kinase/extracellular signal-regulated kinase (ERK) kinase (MEK)/phosphorylated ERK/DNMT1 protein pathway in T-cells from controls and systemic lupus erythematosus patients. J Biol Chem 288, 21936e21944.

48. Sawalha AH and Jeffries M (2007) Defective DNA methylation and CD70 overexpression in CD4+ T cells in MRL/Lpr lupusprone mice. Eur J Immunol 37 (5), 1407-1413. https://doi. org/10.1002/eji.200636872.

49. Basu D, Liu Y, Wu A, et al. (2009) Stimulatory and inhibitory killer Ig-like receptor molecules are expressed and functional on lupus T cells. J Immunol 183 (5), 3481-3487. https://doi. org/10.4049/jimmunol.0900034

50. Hedrich CM, Mabert K, Rauen T, et al. (2017) DNA methylation in systemic lupus erythematosus. Epigenomics 9(4), 505-525.

51. Hedrich CM, Tsokos GC (2011) Epigenetic mechanisms in systemic lupus erythematosus and other autoimmune diseases. Trends Mol Med 17(12): 714-724.

52. Hedrich CM, Crispin JC, Tsokos GC (2014) Epigenetic regulation of cytokine expression in systemic lupus erythematosus with special focus on T cells. Autoimmunity 47(4), 234-241.

53. Wardowska A, Komorniczak M, Bullo-Piontecka B, et al. (2019) Transcriptomic and epigenetic alterations in dendritic cells correspond whit chronic kidney disease in lupus nephritis. Front Immunol 10, 2026.

54. Ropero S and Esteller M (2007) The role of histone deacetylases (HDACs) in human cancer. Mol Oncol 1 (1), 19-25.

55. Kim J-M, To TK \& Seki M (2012) An epigenetic integrator: new insights into genome regulation, environmental stress responses and developmental controls by histone deacetylase 6. Plant Cell Physiol 53(5), 794-800.

56. Cheung P and Lau P (2005) Epigenetic regulation by histone methylation and histone variants. Mol Endocrinol 19(3), 563-573.

57. Sullivan KE, Suriano A, Dietzmann K, et al. (2007) The TNF $\alpha$ locus is altered in monocytes from patients with systemic lupus erythematosus. Clin Immunol 123(1), 74-81.

58. Javierre BM, Richardson B (2011) A new epigenetic challenge: systemic lupus erythematosus. Adv Exp Med Biol 771, 117136. https://doi.org/10.1007/978-1-4419-8216-2_9.

59. Leung YT, Shi L, Maurer K, et al. (2015) Interferon regulatory factor 1 and histone $\mathrm{H} 4$ acetylation in systemic lupus erythematosus. Epigenetics 10(3), 191-199.

60. Zhang Z, Shi L, Song S, et al. (2015) Interferon regulatory factor 1 marks activated genes and can induce target gene expression in systemic lupus erythematosus. Arthritis Rheumatol 67(3), 785-796.

61. Shi L, Zhang Z, Song L, et al. (2015) Monocyte enhancers are highly altered in systemic lupus erythematosus. Epigenomics 7(6), 921-935.
62. Zhang Z, Song L, Maurer K, et al. (2010) Global H4 acetylation analysis by ChIP-chip in systemic lupus erythematosus monocytes. Genes Immun 11(2), 124-133.

63. Leung YT, Maurer K, Song L, et al. (2020) Prolactin activates IRF1 and leads to altered balance of histone acetylation: implications for systemic lupus erythematosus. Mod Rheumatol 30(3), 532-543.

64. Zhang Q, Liao J, Zhao M, et al. (2011) Inhibited expression of hematopoietic progenitor kinase 1associated with loss of jumonji domain containing 3 promote binding contributes to autoimmunity in systemic lupus erythematosus. $J$ Autoimmun 37(3), 180-189.

65. Zhou Y, Qiu X, Luo Y, et al. (2011) Histone modifications and methyl-CpG-binding domain protein levels at the TNFSF7 $(+)$ promoter in SLE CD4+ T cells. Lupus 20(13), 1365-1371.

66. Wu H, Chang C, Lu Q (2020) The epigenetics of lupus erythematosus. Adv Exp Med Biol 1253, 185-207.

67. Zhao X, Tang Y, Qu B, et al. (2010) MicroRNA-125a contributes to elevated inflammatory chemokine RANTES levels via targeting KLF13 in systemic lupus erythematosus. Arthritis Rheum 62(11), 3425-3435.

68. Yin H, Wu H, Zhao M, et al. (2017) Histone demethylase JMJD3 regulates CD11a expression through changes in histone H3K27 tri-methylation levels in CD4+ T cells of patients with systemic lupus erythematosus. Oncotarget 8(30), 4893848947.

69. Liao W, Li M, Wu H, et al. (2017) Down-regulation of MBD4 contributes to hypomethylation and overexpression of CD70 in $\mathrm{CD} 4+\mathrm{T}$ cells in systemic lupus erythematosus. Clin Epigenetics 9, 104

70. Rauen T, Hedrich CM, Juang YT, et al. (2011) cAMP-responsive element modulator (CREM)-protein induces interleukin 17A expression and mediates epigenetic alterations at the interleukin-17A gene locus in patients with systemic lupus erythematosus. J Biol Chem 286(50), 43437-43446.

71. Tenbrock K, Juang YT, Leukert N, et al. (2006) The transcriptional repressor cAMP response element modulator alpha interacts with histone deacetylase 1 to repress promoter activity. J Immunol 177(9), 6159-6164.

72. Crispin JC and Tsokos GC (2009) Transcriptional regulation of IL-2 in health and autoimmunity. Autoimmun Rev 28(3), 190-195.

73. Liu Y, Liao J, Zhao M, et al. (2015) Increased expression of TLR2 in CD4+ T cells from SLE patients enhances immune reactivity and promotes IL-17 expression through histone modifications. Eur J Immunol 45, 2683-2693.

74. Hedrich CM, Rauen T, Apostolidis SA, et al. (2014) Stat3 promotes IL-10 expression in lupus T cells through trans-activation and chromatin remodeling. Proc Natl Acad Sci U S A 111(37), 13457-62.

75. Hu N, Qiu X, Luo Y, et al. (2008) Abnormal histone modification patterns in lupus CD41 T cells. J Rheumatol 35, 804-810.

76. Zhao M, Liu Q, Liang G, et al. (2013) E4BP4 overexpression: a protective mechanism in CD $4+$ T cells from SLE patients. $J$ Autoimmun 41, 152-160.

77. Zhao H, Wang L, Luo H, et al. (2017) TNFAIP3 downregulation mediated by histone modification contributes to T-cell dysfunction in systemic lupus erythematosus. Rheumatology 56(5), 835-843.

78. Lee S, Nakayamada S, Kube S, et al. (2020) Interleukin-23 drives expansion of $\mathrm{T}$ helper 17 cells through epigenetic regulation by signal transducer and activators of Transcription 3 in lupus patients. Rheumatology 59(10), 3058-3069.

79. Von Knethen A, Heinicke U, Weigert A, et al. (2020) Histone deacetylation inhibitors as modulators of regulatory T cells. Int J Mol Sci 21(7), 2356. 
80. Fang EJ, Lin YZ, Liu CC, et al. (2016) Methylation and gene expression of histone deacetylases 6 in systemic lupus erythematosus. Int J Rheu Dis 19(10), 968-973.

81. Wu H, Deng Y, Feng Y, et al. (2018) Epigenetic regulation in B-cell maturation and its dysregulation in autoimmunity. Cell Mol Inmmunol 15(7), 676-684.

82. Pieterse E, Hofstra J, Berden J, et al. (2015) Acetylated histones contribute to the immunostimulatory potential of neutrophil extracellular traps in systemic lupus erythematosus. Clin Exp Immunol 179(1), 68-74.

83. Garcia BA, Busby SA, Shabanowitz J, et al. (2005) Resetting the epigenetic histone code in the MRL-lpr/lpr mouse model of lupus by histone deacetylase inhibition. J Proteome Res 4(6), 2032-2042.

84. Apostolidis SA, Rauen T, Hedrich CM, et al. (2013) Protein phosphatase 2A enables expression of interleukin 17 (IL-17) through chromatin remodeling. J Biol Chem 288 (37), 26775-26784.

85. Kroger A, Koster M, Schroeder K, et al. (2002) Activities of IRF1. J Interferon Cytokine Res 22(1), 5-14.

86. Kyttaris C., Wang, Y., Juang, Y.T., et al. (2006) CAMP response element modulator an expression in patients with systemic lupus erythematosus. Lupus 15 (12), 840-844.

87. Solomou EE, Juang YT, Gourley MF, et al. (2001) Molecular basis of deficient IL-2 production in T cells from patients with systemic lupus erythematosus. JImmunol 166(6), 4216-4222.

88. Zhang W, Ding S, Zhang HL (2017) Effect of aberrant H3K27me3 modification in promoter regions on cAMP response element modulator $\alpha$ expression in $\mathrm{CD} 4+\mathrm{T}$ cells from patients with systemic lupus erythematosus. Nan Fang Yi Ke Da Xие Хие Вао 37(12), 1597-1602.

89. Zhang Q, Ding S, Zhang H, et al. (2016) Increased Set1 binding at the promoter induces aberrant epigenetic alterations and up-regulates cyclic adenosine 5'-monophosphate response element modulator alpha in systemic lupus erythematosus. Clin Epigenet 8(1), 126.

90. Shen N, Liang D, Tang Y, et al. (2012) MicroRNAs - novel regulators of systemic lupus erythematosus pathogenesis. Nat Rev Rheumatol, 1-9.

91. Yan S, Yim LY, Lu L, et al. (2014) MicroRNA regulation in systemic lupus erythematosus pathogenesis. Immune Netw 14, 138-148.

92. Pan W, Zhu S,Dai D, et al. (2015) MiR-125a targets effector programs to stabilize Treg-mediated immune homeostasis. Nature Comm 6, 7096.

93. Smith S, Wu PW, Seo JJ, et al. (2018) IL-16/miR-125a axis controls neutrophil recruitment in pristane-induced lung inflammation. JCI Insight 3(15), e120798.

94. Tang Y, Luo X, Cui H, et al. (2009) MicroRNA-146A contributes to abnormal activation of the type I interferon pathway in human lupus by targeting the key signaling proteins. Arthritis Rheum 60, 1065-1075.

95. Aboelenein HR, Hamza MT, Marzouk H et al. (2017) Reduction of CD19 autoimmunity marker on B cells of paediatric SLE patients through repressing PU. $1 / \mathrm{TNF}-\alpha / \mathrm{BAFF}$ axis pathway by miR-155. Growth Factors 35, (2-3), 49-60.

96. Xin Q, Li J, Dang J, et al. (2015) miR-155 deficiency ameliorates autoimmune inflammation of systemic lupus erythematosus by targeting S1pr1 in Faslpr/lpr mice. J Immunol 194(11), 5437-45.

97. Shumnalieva R, Kachakova D, Shoumnalieva-Ivanova V, et al. (2018) Whole peripheral blood miR-146a and miR-155 expression levels in systemic lupus erythematosus patients. Acta Reumatol Port 43(3), 217-225.

98. Dai R, Phillips RA, Zhang Y, et al. (2008) Suppression of LPSinduced interferon- $\gamma$ and nitric oxide in splenic lymphocytes by select estrogen-regulated microRNAs: a novel mechanism of immune modulation. Blood 112, 4591-1597.

99. Pan W, Zhu S, Yuan M, et al. (2010) MicroRNA-21 and microRNA-148a contribute to DNA hypomethylation in lupus CD4 + T cells by directly and indirectly targeting DNA methyltransferase 1. J Immunol 184(12): 6773-6781.

100. Zhao S, Wang Y, Liang Y, et al. (2011) MicroRNA-126 regulates DNA methylation in CD4+ T cells and contributes to systemic lupus erythematosus by targeting DNA methyltransferase-1. Arhtritis Rheum 63(5), 1376-1386.

101. Ding S, Liang Y, Zhao M, et al. (2012) Decreased microRNA$142-3 \mathrm{p} / 5 \mathrm{p}$ expression causes CD4 $+\mathrm{T}$ cell activation and B cell hyperstimulation in systemic lupus erythematosus. Arthr Rheum 64, 9.

102. Fan W, Liang D, Tang Y, et al. (2012) Identification of miRNA31 as a novel regulator contributing to impaired interleukin-2 production on T cells from patients with SLE. Arth Rheum 64(11), 3715-3725.

103. Qin H, Zhu X, Liang J, et al. (2013) MicroRNA-29b contributes to DNA hypomethylation of $\mathrm{CD} 4+\mathrm{T}$ cells in systemic lupus erythematosus by indirectly targeting DNA methyltransferase 1.J Dermatol Sci 69, 61-7. doi: 10.1016/j.jdermsci.2012. 10.011

104. Coit P, Dozmorov MG, Merrill JT, et al. (2016) Epigenetic reprogramming in naive $\mathrm{CD} 4+\mathrm{T}$ cells favoring $\mathrm{T}$ cell activation and non-Th1 effector $\mathrm{T}$ cell immune response as an early event in lupus flares. Arthritis Rheumatol 68, 2200-9. doi: 10. 1002/art.39720

105. Luo S, Liu Y, Liang G, et al. (2015) The role of microRNA-1246 in the regulation of $\mathrm{B}$ cell activation and the pathogenesis of systemic lupus erythematosus. Clin Epigenet 7(1), 1.

106. Rao DS, O'Connell RM, Chaudhuri AA, et al. (2010) MicroRNA$34 \mathrm{a}$ perturbs B lymphocyte development by repressing the forkhead box transcription factor Foxp1. Immunity 33 (1), 48-59.

107. Xiao C, Calado DP, Galler G et al. (2007) MiR-150 controls B cell differentiation by targeting the transcription factor c-Myb. Cell 131 (1), 146-159.

108. de Yebenes VG, Belver L, Pisano DG et al. (2008) miR-181b negatively regulates activation-induced cytidine deaminase in B cells. J Exp Med 205 (10), 2199-2206.

109. Zhao CN, Mao YM, Liu LN, et al. (2018) Emerging role of IncRNAs in systemic lupus erythematosus. Biomed Pharmacother 106, 584-592.

110. Zhang F, Wu L, Qian J, et al. (2016) Identification of the long noncoding RNA NEAT1 as novel inflammatory regulator acting through MAPK pathway in human lupus. J Autoimmun 75, 96-104.

111. Wu GC, Li J, Leng RX, et al. (2017) Identification of long noncoding RNAs GAS5, linc0597 and lnc-DC in plasma as novel biomarkers for systemic lupus erythematosus. Oncotarget $\mathbf{8}$, 23650-23663.

112. Tsai CY, Hsieh SC, Lu CS, et al. (2019) Cross-talk between mitochondrial dysfunction-provoked oxidative stress and aberrant noncoding RNA expression in the pathogenesis and pathophysiology of SLE. Int J Mol Sci $\mathbf{2 0}, 5186$.

113. Jiang CR and Li TH (2018) Circulating UCA1 is highly expressed in patients with systemic lupus erythematosus and promotes the progression through the AKT pathway. Eur Rev Med Pharmacol Sci 22, 2364-71. doi: 10.26355/ eurrev_201804_14828

114. Stagakis E, Bertsias G, Verginis P, et al. (2011) Identification of novel microRNA signatures linked to human lupus disease activity and pathogenesis: miR-21 regulates aberrant $\mathrm{T}$ cell responses through regulation of PDCD4 expression. Ann Rheum Dis 70, 1496-1506. 
115. Lashine YA, Salah S, Aboelenein HR, et al. (2015) Correcting the expression of miRNA-155 represses PP2Ac and enhances the release of IL-2 in PBMCs of juvenile SLE patients. Lupus 24, 240-247.

116. Gao X, Liu L, Min X, et al. (2020) Non-coding RNAs in CD4+ T cells: new insights into the pathogenesis of systemic lupus erythematosus. Front Immunol 11, 568.

117. Stypinska B, Paradowska-Gorycka A (2015) Cytokines and microRNAs as candidate biomarkers for systemic lupus erythematosus. Int J Mol Sci 16, 24194-24218.

118. Suo, Q.F., Sheng, J., Qiang, F.Y., et al. (2018) Association of long non-coding RNA GAS5 and miR-21 levels in CD4+ T cells with clinical features of systemic lupus erythematosus. Exp Ther Med. doi: 10.3892/etm.2017.5429

119. Li LJ, Zhao W, Tao SS, et al. (2017) Comprehensive long noncoding RNA expression profiling reveals their potential roles in systemic lupus erythematosus. Cell Immunol. doi: 10. 1016/j.cellimm.2017.06.004

120. Shaker OG, Nassar YH, Gheta TA, et al. (2020) LncRNAs as new biomarkers in systemic lupus erythematosus: a prospective study. Indian J Public Health 11, 2.

121. Gravina GL, Festuccia C, Marampon F, et al. (2010) Biological rationale for the use of DNA methyltransferase inhibitors as new strategy for modulation of tumor response to chemotherapy and radiation. Mol Cancer 25, 9, 305. https://doi. org/10.1186/1476-4598-9-305.

122. Marques-Magalhães A, Graça I, Henrique R, et al. (2018) Targeting DNA methyltransferases in urological tumors. Front Pharmacol 9, 366

123. Chistiakov DA, Orekhov AN, Bobryshev YV (2017) Treatment of cardiovascular pathology with epigenetically active agents: focus on natural and synthetic inhibitors of DNA methylation and histone deacetylation. Int J Cardiol 227, 66-82.

124. Cuvillier O, Schulz WA, Rollins RA, et al. (2018) Targeting DNA methyltransferases in urological tumors. Front Pharmacol 1, 366. https://doi.org/10.3389/fphar.2018.00366.

125. Richardson B (2007) Primer: epigenetics of autoimmunity. Nat Clin Pract Rheumatol 3, 521-527.

126. Strickland FM and Richardson BC (2008) Epigenetics in autoimmunity - DNA methylation in systemic lupus erythematosus and beyond. Autoimmunity 41(4), 278.

127. Somers EC and Richardson BC (2014) Environmental exposures, epigenetic changes and the risk of lupus. Lupus $\mathbf{2 3}(6), 568-576$.

128. Zhang L, Lu Q, Chang C (2020) Epigenetics in health and disease. In: Chang C, Lu Q. (eds) Epigenetics in Allergy and Autoimmunity. Adv Exp Med Biol 1253. https://doi.org/10. 1007/978-981-15-3449-2_1

129. Gowher H, Jeltsch A (2004) Mechanism of inhibition of DNA methyltransferases by cytidine analogs in cancer therapy. Cancer Biol Ther 3(11), 1062-68. https://doi.org/10.4161/ cbt.3.11.1308.

130. Cheng JC, Yoo CB, Weisenberger DJ, et al. (2004) Preferential response of cancer cells to zebularine. Cancer Cell 6(2), 15158. https://doi.org/10.1016/j.ccr.2004.06.023.

131. Mai A, Altucci L (2009) Epi-drugs to fight cancer: from chemistry to cancer treatment, the road ahead. Int J Biochem Cell Biol. https://doi.org/10.1016/j.biocel.2008.08.020.

132. Srivastava P, Paluch BE, Matsuzaki J, et al. (2015) Immunomodulatory action of the DNA methyltransferase inhibitor SGI-110 in epithelial ovarian cancer cells and xenografts. Epigenetics 10 (3), 237-246. https://doi.org/10.1080/ 15592294.2015 .1017198

133. Lee BH, Yegnasubramanian S, Lin X, et al. (2005) Procainamide is a specific inhibitor of DNA methyltransferase
1. I Biol Chem 280, 40749-40756. doi: 10.1074/jbc. M505593200

134. Li H, Zhang W, Zhong F, et al. (2018) Epigenetic regulation of RCAN1 expression in kidney disease and its role in podocyte injury. Kidney Int 94 (6), 1160-76. https://doi.org/10.1016/j. kint.2018.07.023.

135. Lewis EC, Blaabjerg L, Storling J, et al. (2011) The oral histone deacetylase inhibitor ITF2357 reduces cytokines and protects islet $\beta$ cells in vivo and in vitro. Mol Med 17 (5-6), 369-377.

136. Munro SK, Mitchell MD, Ponnampalam AP (2013) Histone deacetylase inhibition by trichostatin A mitigates LPS induced TNF $\alpha$ and IL-10 production in human placental explants. Placenta 34(7), 567-573.

137. Grabiec AM, Krausz S, de Jager W, et al. (2010) Histone deacetylase inhibitors suppress inflammatory activation of rheumatoid arthritis patient synovial macrophages and tissue. $J$ Immunol 184(5), 2718-2728.

138. Reilly CM, Thomas M, Gogal R Jr., et al. (2008) The histone deacetylase inhibitor trichostatin A upregulates regulatory $\mathrm{T}$ cells and modulates autoimmunity in NZB/W F1 mice. $J$ Autoimmun 31(2), 123-130.

139. Mishra N, Reilly CM, Brown DR, et al. (2003) Histone deacetylase inhibitors modulate renal disease in the MRL-lpr/lpr mouse. J Clin Investig 101(4), 539-552.

140. Mishra N, Brown DR, Olorenshaw IM, et al. (2001) Trichostatin A reverses skewed expression of CD154, interleukin-10, and interferon-g gene and protein expression in lupus T cells. Proc Natl Acad Sci $\mathbf{9 8}(5), 2628-2633$.

141. Regna NL, Vieson MD, Luo XM, et al. (20169 Specific HDAC6 inhibition by ACY-738 reduces SLE pathogenesis in NZB/W mice. Clin Immunol 162, 58-73.

142. Choi EW, Song JW, Ha N, et al. (2018) CKD-506, a novel HDAC6-selective inhibitor, improves renal outcomes and survival in a mouse model of systemic lupus erythematosus. Sci $\operatorname{Rep} \mathbf{8}(1), 17297$.

143. Regna NL, Chafin CB, Hammond SE, et al. (2014) Class I and II histone deacetylase inhibition by ITF2357 reduces SLE pathogenesis in vivo. Clin Immunol 151(1), 29-42.

144. Burke M, Lamba KJ, Pound S, et al. (2014) A therapeutic trial of decitabine and vorinostat in combination with chemotherapy for relapsed/refractory acute lymphoblastic leukemia. $A m \mathrm{~J}$ Hematol 89(9), 889-895.

145. Duvic M, Vu J (2006) Vorinostat: a new oral histone deacetylase inhibitor approved for cutaneous T-cell lymphoma. Expert Opin Investig Drugs 16(7), 1111-1120.

146. Störman S, Schophl J (2018) New and emerging drug therapies for Cushing's disease. Expert Opin Pharmacother 19(11), $1187-1200$.

147. Iwamoto M, Friedam EJ, Sandhu P,, et al. (2013) Clinical pharmacology profile of vorinostat, a histone deacetylase inhibitor. Cancer Chemother Pharmacol 72(3), 493-508.

148. Mamdani H, Jalal SI (2020) Histone deacetylase in non-small cell lung cancer: hype or hope? Front Cell Dev Biol 8, 582370.

149. Pinto N, DuBois S, Marachelian A, et al. (2018) HDAC inhibitors in acute myeloid leukemia. Pediatr Blood Cancer 65(7), e27023.

150. Vojinovic J, Damjanov N, D'Urzo C, et al. (2011) Safety and efficacy of an oral histone deacetylase inhibitor in systemiconset juvenile idiopathic arthritis. Arthritis Rheum 63(5), $1452-1458$.

151. Bettica P, Petrini S, D'Oria V, et al. (2016) Histological effects of givinostat in boys with Duchenne muscular dystrophy. Neuromuscul Disord 26(10), 643-649.

152. Nobs SP, Zmora N, Elinav E (2020) Nutrition regulates innate immunity in health and disease. Annu Rev Nutr 40, 189-219. 
153. Szarc K, Ndlovu MN, Haegeman G, et al. (2010) Nature or nurture: let food be your epigenetic medicine in chronic inflammatory disorders. Biochem Pharmacol Elsevier Inc 80(12), 1816-1832.

154. Venter C, Eyerich S, Sarin T, et al. (2020) Nutrition and the immune system: a complicated tango. Nutrients 12, 818 .

155. Barrea L, Muscogiuri G, Frias-Toral E, et al. (2020) Nutrition and immune system: from the Mediterranean diet to dietary supplementary through the microbiota. Crit Rev Food Sci. https://doi.org/10.1080/10408398.2020.1792826

156. Mentella MC, Scaldaferri F, Ricci C, et al. (2019) Cancer and Mediterranean diet: a review. Nutrients 11(9), 2059. https:// doi.org/10.3390/nu11092059.

157. Gardener H and Caunca MR (2018) Mediterranean diet in preventing neurodegenerative diseases. Curr Nutr Rep 7(1), 1020. https://doi.org/10.1007/s13668-018-0222-5.

158. Estruch R (2010) Anti-inflammatory effects of the Mediterranean diet: the experience of the PREDIMED study. Proc Nutr Soc 69(3), 333-340. https://doi.org/10.1017/ S0029665110001539

159. Casas R, Sacanella E, Estruch R (2014) The immune protective effect of the Mediterranean diet against chronic low-grade inflammatory diseases. Endocr Metab Immune Disord Drug Targets 14, 245-254.

160. La Cava A (2019) The influence of diet and obesity on gene expression in SLE. Genes 10, 405.

161. Islam MA, Khandker SS, Kotyla PJ, et al. (2020) Immunomodulatory effects of diet and nutrients in systemic lupus erythematosus (SLE): a systematic review. Front Immunol 11(July), 1-17.

162. de Medeiros MCS, Medeiros JCA, de Medeiros HJ, et al. (2019) Dietary intervention and health in patients with systemic lupus erythematosus: a systematic review of the evidence. Crit Rev Food Sci Nutr 59(16), 2666-73.

163. Mckay JA and Mathers JC (2011) Diet induced epigenetic changes and their implications for health. Acta Physiol 202(2), 103-118.

164. Franzago M, Santurbano D, Vitacolonna E (2020) Genes and diet in the prevention of chronic diseases in future generations. Int J Mol Sci 21, 2633.

165. Corella D, Coltell O, Macian F, Ordovás JM (2018) Advances in understanding the molecular basis of the Mediterranean diet effect. Annu Rev Food Sci Technol 25, 9, 227-249. https:// doi.org/10.1146/annurev-food-032217-020802.

166. Ideraabdullah FY and Zeisel SH (2018) Dietary modulation of the epigenome. Physiol Rev 98(2), 667-695.

167. Ng GY, Fann DY, Jo D, et al. (2019) Epigenetic regulation by dietary restriction: part II. Cond Med 2(6), 300-310.

168. Ng GY, Fann DY, Jo D, et al. Restriction and epigenetics: part I. Cond Med 2(6), 284-299.

169. Li Y, Liu Y, Strickland FM, et al. (2010) Age-dependent decreases in DNA methyltransferase levels and low transmethylation micronutrient levels synergize to promote overexpression of genes implicated in autoimmunity and acute coronary syndromes. Exp Gerontol 45(4), 312-322.

170. Strickland FM, Hewagama A, Wu A, et al. (2013) Diet influences expression of autoimmune associated genes and disease severity by epigenetic mechanism in a transgenic lupus model. Arthritis Rheum 65(7), 1872-1881.

171. Ray D, Strickland FM, Richardson BC (2018) Oxidative stress and dietary micronutrient deficiencies contribute to overexpression of epigenetically regulated genes by lupus $\mathrm{T}$ cells. Clin Immunol 196, 97-102,

172. Evans LW, Stratton S, Ferguson BS (2020) Dietary natural products as epigenetic modifiers in aging-associated inflammation and disease. Nat Prod Rep 37, 653-676.
173. Hardy TM, Tollefsbol TO (2011) Epigenetic diet: impact on the epigenome and cancer. Epigenomics 3(4):503-518.

174. Boyanapalli SS, Kong, A-N.T. (2015) "Curcumin, the king of spices": epigenetic regulatory mechanisms in the prevention of cancer, neurological, and inflammatory diseases. Curr Pharmacol Rep 1, 129-139.

175. Handono K, Pratama MZ, Endharti AT, et al. (2015) Treatment of low doses curcumin could modulate Th17/Treg balance specifically on CD4+ T cell cultures of systemic lupus erythematosus patients. Cent Eur J Immunol 40, 461-469.

176. Momtazi-Borojeni AA, Haftcheshmeh SM, Esmaeili SA, et al. (2018) Curcumin: a natural modulator of immune cells in systemic lupus erythematosus. Autoimmun Rev 17, 125-135.

177. Dent EL, Taylor EB, Turbeville HR, et al. (2020) Curcumin attenuates autoimmunity and renal injury in an experimental model of systemic lupus erythematosus. Physiol Rep 8(13), e14501. https://doi.org/10.14814/phy2.14501.

178. Khajehdehi P, Zanjaninejad B, Aflaki E, et al. (2012) Oral supplementation of turmeric decreases proteinuria, hematuria, and systolic blood pressure in patients suffering from relapsing or refractory lupus nephritis: a randomized and placebocontrolled study. J Renal Nutr 22, 50-57.

179. Constantin MM, Nita IE, Olteanu R, et al. (2019) Significance and impact of dietary factors on systemic lupus erythematosus. Exp Ther Med 17(2), 1085-1090.

180. Kumari, A., Bhawal, S., Kapila, S., et al. (2020) Health-promoting role of dietary bioactive compounds through epigenetic modulations: a novel prophylactic and therapeutic approach. Crit Rev Food Sci Nutr. https://doi.org/10.1080/10408398. 2020.1825286

181. Balasubramanyam K, Varier RA, Altaf M, et al. (2004) Curcumin, a novel p300/CREB-binding protein-specific inhibitor of acetyltransferase, represses the acetylation of histone/nonhistone proteins and histone acetyltransferase-dependent chromatin transcription. J Biol Chem 279, 5116351171

182. Tsai PY, Ka SM, Chang JM, et al. (2011) Epigallocatechin-3-gallate prevents lupus nephritis development in mice via enhancing the Nrf2 antioxidant pathway and inhibiting NLRP3 inflammasome activation. Free Radic Biol Med 51, 744-754.

183. Kanlaya R, Thongboonkerd V (2019) Molecular mechanisms of epigallocatechin-3-gallatefor prevention of chronic kidney disease and renal fibrosis: preclinical evidences. Curr Dev Nutri 3(9), nzz101.

184. Sayama K, Oguni I, Tsubura A, et al. (2003) Inhibitory effects of autoimmune disease by green tea in MRL-Faslprcg/Faslprcg mice. In Vivo 17(6), 545-552.

185. Thakur, V.S., Gupta, K., Gupta, S. (2012) Green tea polyphenols causes cell cycle arrest and apoptosis in prostate cancer cells by suppressing class I histone deacetylases. Carcinogenesis 33, 377-384.

186. Fang MZ, Wang Y, Ai N, et al. (2003) Tea polyphenol (-)-epigallocatechin-3-gallate inhibits DNA methyltransferase and reactivates methylation-silenced genes in cancer cell lines. Cancer Res 63(22), 7563-7570.

187. Wong CP, Nguyen LP, Noh SK, et al. (2011) Induction of regulatory $\mathrm{T}$ cells by green tea polyphenol EGCG. Immunol Lett 139, 7-13.

188. Nakata R, Takahashi S, Inoue H (2012) Recent advances in the study on resveratrol. Biol Pharm Bull 35, 273-279.

189. Wang ZL, Luo XF, Li MT, et al. (2014) Resveratrol possesses protective effects in a pristane-induced lupus mouse model. PLoS One 9(12), e114792.

190. Roy SK, Chen Q, Fu J, et al. (2011) Resveratrol inhibits growth of orthotopic pancreatic tumors through activation of FOXO transcription factors. PLoS One 6(9): e25166. 
191. Song J, Jun M, Ahn MR, et al. (2016) Involvement of miR-Let7A in inflammatory response and cell survival/apoptosis regulated by resveratrol in THP-1 macrophage. Nutr Res Pract 10(4), 377-384.

192. Auborn KJ, Qi M, Yan XJ, et al. (2003) Lifespan is prolonged in autoimmune-prone (NZB/NZW) F1 mice fed a diet supplemented with indole-3-carbinol. J Nutr 133, 3610-3613.

193. Eghbalpour F, Aghaei M, Ebrahimi M, et al. (2020) Effect of indole-3-carbinol on transcriptional profiling of wound-healing genes in macrophages of systemic lupus erythematosus patients: an RNA sequencing assay. Lupus 29(8), 954-963. doi: 10.1177/0961203320929746

194. Busbee PB, Nagarkatti M, Nagarkatti PS (2014) Natural indoles, indole-3-carbinol and 3,3'-diinolymethane, inhibit T cell activation by staphylococcal enterotoxin $\mathrm{B}$ through epigenetic regulation involving HDAC expression. Toxicol Appl Pharmacol 274(1).

195. Busbee PB, Nagarkatti M, Nagarkatti PS (2015) Natural indoles, indole-3-carbinol (I3C) and 3,3'-diinolymethane (DIM), attenuate staphylococcal enterotoxin B-mediated liver injury by downregulating miR31 expression and promoting caspase-2-mediated apoptosis. PLOS ONE 10(2), e0118506.

196. Li Y, Chen F, Wei A, et al. (2019) Klotho recovery by genistein via promoter histone acetylation and DNA demethylation mitigates renal fibrosis in mice. J Mol Med $\mathbf{9 7}, 4$.
197. De la Parra C, Castillo-Pichardo L, Cruz-Collazo A, et al. (2016) Soy isoflavone genistein-mediated downregulation of miR-155 contributes to the anticancer effects of genistein. Nutr Cancer 68 (1), 154-64. doi: 10.1080/01635581.2016. 1115104

198. Aparicio-Soto M, Sánchez-Hidalgo M, Cárdeno A, et al. (2016) Dietary extra virgin olive oil attenuates kidney injury in pristine-induced SLE model via activation of HO-1/Nrf-2 antioxidant pathway and suppression of JAK/STAT, NF-kB and MAPK activation. J Nutr Biochem 27, 278-288.

199. Aparicio-Soto M, Sánchez-Hidalgo M, Cárdeno A, et al. (2017) Polyphenolic fraction of extra virgin olive oil modulates the activation and the inflammatory response of $\mathrm{T}$ cells patients with systemic lupus erytematosus and healthy donors. $\mathrm{Mol}$ Nutr Food Res 61(8), 1601080.

200. Arpón A, Milagro FI, Razquin C, et al. (2018) Impact of consuming extra-virgin olive oil or nuts within a Mediterranean diet on DNA methylation in peripheral white blood cells within the PREDIMED-Navarra randomized controlled trial: a role for dietary lipids. Nutrients $\mathbf{1 0}, 15$.

201. Nanda N, Mahmood S, Bhatia A, et al. (2019) Chemopreventive role of olive oil in colon carcinogenesis by targeting noncoding RNAs and methylation. Int J Cancer 144, 1180-1194. 